\title{
REVIEWS
}

\section{Immune checkpoint blockade in infectious diseases}

\section{Michelle N. Wykes ${ }^{1}$ and Sharon R. Lewin ${ }^{2,3}$}

Abstract | The upregulation of immune checkpoint molecules, such as programmed cell death protein 1 (PD1) and cytotoxic T lymphocyte antigen 4 (CTLA4), on immune cells occurs during acute infections, such as malaria, as well as during chronic persistent viral infections, including HIV and hepatitis B virus. These pathways are important for preventing immune-driven pathology but can also limit immune-mediated clearance of the infection. The recent success of immune checkpoint blockade in cancer therapy suggests that targeting these pathways would also be effective for preventing and treating a range of infectious diseases. Here, we review our current understanding of immune checkpoint pathways in the pathogenesis of infectious diseases and discuss the potential for therapeutically targeting these pathways in this setting.

Immune checkpoint molecules are inhibitory receptors expressed on immune cells that trigger immunosuppressive signalling pathways. These molecules are crucial for maintaining self-tolerance and for modulating the length and magnitude of effector immune responses in peripheral tissues to minimize collateral tissue damage ${ }^{1,2}$. Signalling through these molecules can drive effector immune cells (especially T cells) into a state known as 'exhaustion'. T cell exhaustion is defined by reduced effector function, sustained expression of immune checkpoint molecules (such as programmed cell death protein 1 (PD1)), poor recall responses and a transcriptional state distinct from that of functional effector or memory $\mathrm{T}$ cells ${ }^{3}$. There are numerous types of activating and inhibitory interactions that occur between antigen-presenting cells (APCs) and T cells, and these interactions regulate the nature of immune responses (FIG. 1). It is now clear that many pathogens and cancers promote inhibitory interactions between immune cells through immune checkpoint proteins to escape immune control.

Investigation of these immunosuppressive interactions has led to the clinical development and licensing of new cancer treatments, which increase immune responses by using specific antibodies to block immune checkpoint molecules (BOX 1). Antibodies targeting PD1 (pembrolizumab, nivolumab), cytotoxic T lymphocyte antigen 4 (CTLA4) (ipilimumab) and programmed cell death 1 ligand 1 (PDL1, also known as B7-H1) (atezolizumab, avelumab and durvalumab) are currently licensed as monotherapies for various types of cancer (BOX 2). In addition, combined therapeutic targeting of PD1 and CTLA4 was shown to be more effective than either therapy alone for treatment of melanoma ${ }^{4}$, although such combination therapy also leads to increased toxicity in patients. Therapies targeting several other immune checkpoint pathways have also shown promise for controlling various types of cancer (TABLE 1; reviewed in REF. 2). It is also possible to increase immunity by directly targeting co-stimulatory molecules on $\mathrm{T}$ cells with agonistic antibodies (BOX 1), and the clinical utility of such treatments is currently being assessed in clinical trials. These antibody-mediated treatments use the individual's own immune system to eliminate or slow the growth of cancer cells and have shown remarkable success in malignancies such as melanoma.

A major challenge in immunotherapy is to understand why treatment responses are variable, and thus there is a search for predictive 'biomarkers' of a favourable clinical response. PDL1 expression on tumour cells can identify patients who would most benefit from PD1 or PDL1 blockade therapy ${ }^{5}$. There are also more complex 'gene signatures' in tumours that can identify patients who will show the best responses to immunotherapies ${ }^{6}$. Earlier expansion of $\mathrm{T}$ cell populations following anti-PD1 antibody therapy in small-cell lung cancer has been associated with improved responses ${ }^{7}$, and a composite biomarker of the T cell proliferative response together with pretreatment tumour burden can predict responses to anti-PD1 antibody in individuals with metastatic melanoma ${ }^{8}$. Given the cost and toxicity of immune checkpoint blockade, identifying biomarkers that predict a clinical response is currently a top priority.

Whether immunotherapies can also be effective for treating infectious diseases is less well explored. However, the fact that these inhibitory pathways are also 


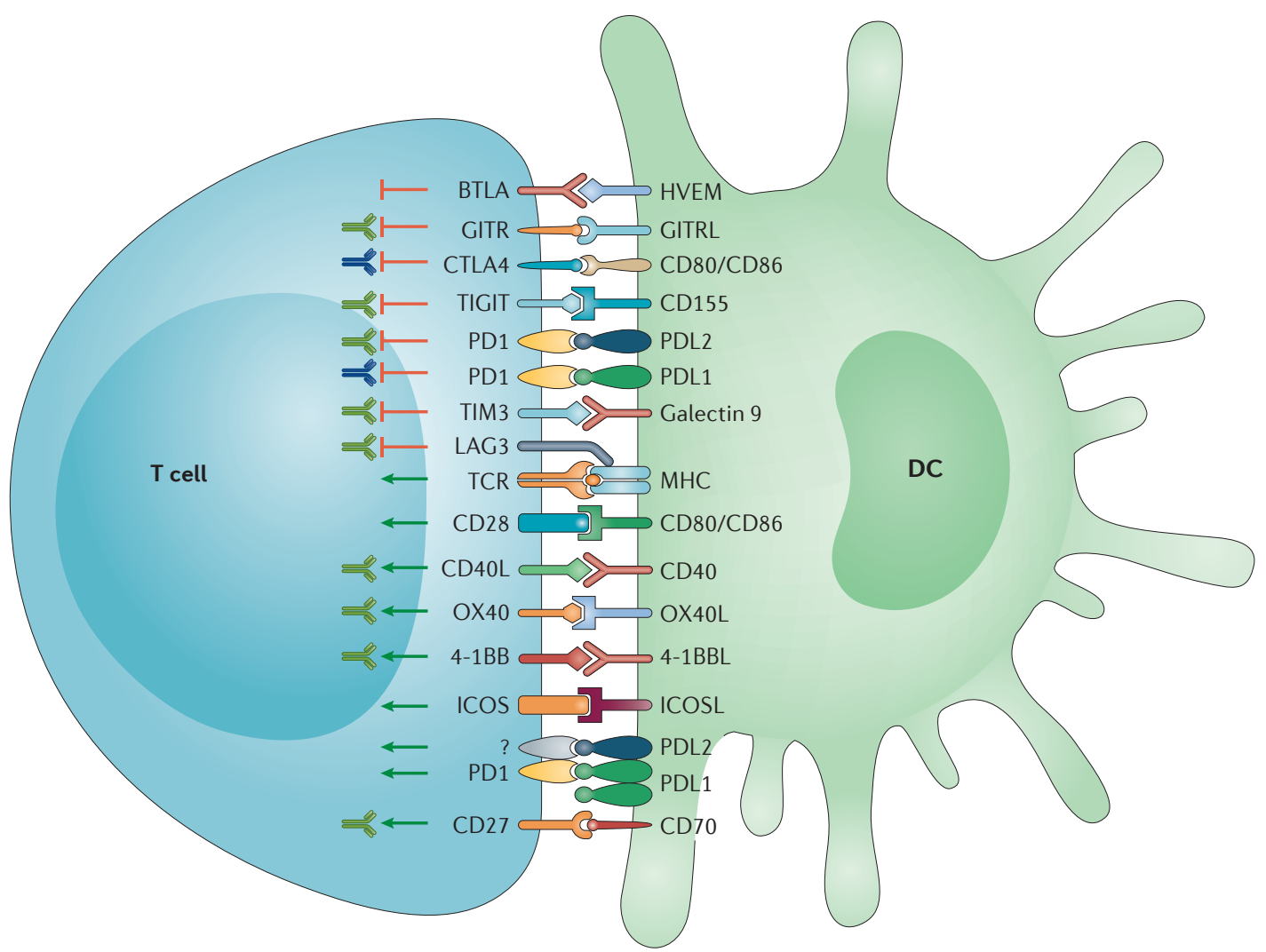

Figure 1 Interactions with antigen-presenting cells that regulate T cell responses. Antigen-presenting cells (APCs), such as dendritic cells (DCs), regulate antigen-specific T cell responses to pathogens or malignant cells. The T cell receptors (TCRs) on antigen-specific T cells first recognize their cognate antigens, which are presented on MHC molecules on APCs (signal 1). This step must be followed by a signal to CD28 on T cells from CD80 on the APCs, which is described as 'signal 2'. Several different ligands on DCs then provide signals to T cells that determine the quality and duration of the effector response. Receptor-ligand interactions that amplify effector T cell responses (indicated by green arrows) include CD40CD40 ligand (CD40L), OX40-OX40L, 4-1BB-4-1BBL (also known as CD137L), inducible T cell co-stimulator (ICOS)-ICOSL and CD27-CD70. There are also receptor-ligand interactions that suppress effector T cell responses (red square arrows) to maintain self-tolerance and limit the duration of the immune responses to minimize bystander damage to host tissue. These include lymphocyte activation gene 3 protein (LAG3)-MHC class II, T cell immunoglobulin mucin receptor 3 (TIM3)galectin 9, programmed cell death protein 1 (PD1)-programmed cell death 1 ligand 1 (PDL1), PD1-PDL2, T cell immunoreceptor with immunoglobulin and ITIM domains (TIGIT)-CD155, cytotoxic T lymphocyte antigen 4 (CTLA4)-CD86 or CTLA4-CD80, glucocorticoid-induced TNFR-related protein (GITR)-GITR ligand (GITRL) and B and T lymphocyte attenuator (BTLA)-herpes virus entry mediator (HVEM). The '?' refers to an unknown receptor that 'activates' T cells. Antibody symbols represent pathways being tested in current clinical trials. The green antibodies indicate pathways undergoing clinical trials for cancer, and the dark blue antibodies indicate those already in clinical use.

exploited for immune evasion by pathogens suggests that their blockade could be used for the prevention and treatment of infectious diseases, in either the acute or chronic phases of infection. Currently, checkpoint blockade is being evaluated for reversing $\mathrm{T}$ cell exhaustion that follows from chronic infectious disease, but there is potential for also treating acute infections to generate long-term immunity ${ }^{9}$. The development of vaccines for a range of infectious diseases, including malaria, hepatitis $\mathrm{B}$ virus (HBV) and HIV could also potentially be improved through immune checkpoint blockade. Given that drug resistance in malaria ${ }^{10}$ and many other infections is increasing and that control of both HIV and HBV requires lifelong treatment, new strategies for potentially curing these infections are being considered. Furthermore, parallel searches for biomarkers that will provide information on the best therapy choice as well as indicate if there is a time frame when immunotherapy would be most efficacious are also required. In this Review, we describe in detail the impact of immune checkpoint signalling during malaria, HIV and HBV infections, as well as in tuberculosis (TB), and we discuss the potential for therapeutically targeting these pathways in these settings.

\section{Immune checkpoint proteins in malaria}

Malaria is a mosquito-borne infectious disease of humans caused by parasitic protozoans of the genus Plasmodium. The majority of malaria infections are caused by Plasmodium falciparum and Plasmodium vivax, and in 2015, there were 212 million new cases of malaria worldwide, with 429,000 deaths due to $P$. falciparum alone ${ }^{11}$. These parasites have a complex 
life cycle within the mammalian host, in which a liver stage of infection is followed by asexual and sexual blood stages of infection. The blood stages cause the severe symptoms and high mortality associated with malaria.

Over the past 20 years, more than 100 vaccines have been developed to control malaria, and these have been clinically evaluated. Most vaccines were specifically designed to target liver-stage or blood-stage parasites by inducing protective antibodies and $\mathrm{CD} 4^{+} \mathrm{T}$ cells, although a few vaccines were designed to generate $\mathrm{CD} 8^{+}$ $\mathrm{T}$ cell responses against the liver-stage parasites. The best candidate vaccine identified to date is the RTS,S/AS01E vaccine, which will soon be administered to children in Africa; however, this vaccine had an efficacy of only $43.6 \%$ in the first year of administration, and efficacy decreased to $16.8 \%$ by the fourth year ${ }^{12}$. This result highlights considerable challenges in developing an effective malaria vaccine and suggests that new strategies that target potential mechanisms of immune evasion by parasites need consideration.

The symptoms of malaria range from asymptomatic to chronic, severe and finally lethal disease. Partial immunity is developed by those living in endemic areas only

\section{Box 1 | Immunotherapy for treating cancer}

Immunotherapy is a type of treatment designed to boost the body's natural immune response to cancer. There are currently two main types of immunotherapy (see the figure). First, antibodies can block immunosuppressive interactions between antigen-presenting cells or cancer cells and effector cells (for example, T cells) to improve immune responses. For example, stimulatory signals to $T$ cells from corresponding ligands (part a) are attenuated when T cell receptor (TCR) signalling is coincident with inhibitory receptors interacting with their ligands (part b), which decreases the magnitude of responses by T cells. Antibody blockade of the inhibitory receptor-ligand interaction or interactions reinstates T cell functions (part c). The two best examples are blockade of programmed cell death protein 1 (PD1) and cytotoxic $T$ lymphocyte antigen 4 (CTLA4), which are both expressed on effector T cells and mediate exhaustion when in contact with their ligands, programmed cell death 1 ligand 1 (PDL1) for PD1 and CD80 (also known as B7-1) and CD86 (also known as B7-2) for CTLA4. The second type of immunotherapy uses antibodies that directly 'activate' $T$ cells via activating receptors (part d). Two examples of this type of therapy are targeting OX40 and 4-1BB (also known as CD137) on T cells to improve their respective functions. While the development of immunotherapy has been restricted to the treatment of cancer, there is strong interest in the role of these antibodies in infectious diseases.

a

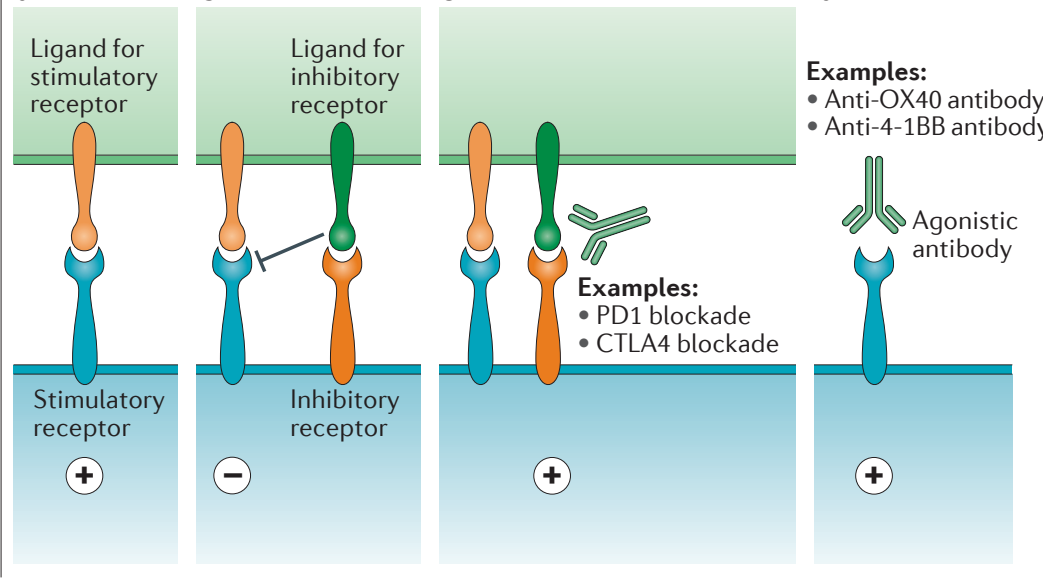

after repeated malarial infection over several years ${ }^{13-15}$. Protection against malaria is dependent on both cellmediated and humoral immune responses. Parasites in the liver stage are known to be cleared by cytotoxic $\mathrm{CD}^{+} \mathrm{T}$ cells and possibly CD $4^{+} \mathrm{T}$ cells ${ }^{16}$. For blood-stage malaria, antibodies have been shown to play a key role in protection, as demonstrated by the transfer of serum from protected adults into children ${ }^{17}$. Studies in experimental rodent models of malaria have shown that multiple effector responses are required to protect against blood-stage malaria. T helper $1\left(\mathrm{~T}_{\mathrm{H}} 1\right)$ cell responses are critical for controlling the bulk of blood-stage parasites and thus preventing severe disease ${ }^{18,19}$. Antibodies are required to eliminate the remaining patent parasites ${ }^{20}$. Recent studies have shown that $\mathrm{CD} 8^{+} \mathrm{T}$ cells are required for sterile immunity that prevents the acute infection from progressing to chronic malaria ${ }^{21}$. Antibodies and $\mathrm{CD}^{+} \mathrm{T}$ cells are also required for long-term protection against reinfection ${ }^{22}$. Studies have also shown that malarial infections caused apoptosis of vaccine-specific memory B cells ${ }^{23}$ because of compromised dendritic cell (DC) functions ${ }^{24}$. This could explain why vaccines have not been successful in the field. Several other factors also contribute to short-lived immunity against malaria (reviewed in REF. 25), but the role of PD1 as a major factor in loss of immunity against malaria has risen to the forefront.

Malaria and T cell exhaustion. As vaccines have been the focus of malaria control, the study of immune checkpoint proteins in malaria infections is fairly new. Field studies in malaria-endemic Mali and Kenya found that individuals recently infected with $P$. falciparum expressed $\mathrm{PD} 1$ on $\mathrm{CD}^{+}$(REFS 26,27) and $\mathrm{CD}^{+} \mathrm{T}^{-}$cells ${ }^{27}$, implicating this molecule in immune evasion. Similarly, an increased proportion of $\mathrm{CD}^{+} \mathrm{T}$ cells from individuals with acutephase infections with $P$. vivax, $P$. falciparum or both had increased expression of CTLA4, OX40 (also known as TNFRSF4), glucocorticoid-induced TNFR-related protein (GITR; also known as TNFRSF18) and CD69 (REF. 28), suggesting a role for regulatory $\mathrm{T}\left(\mathrm{T}_{\text {reg }}\right)$ cells in suppressing immunity to malaria and indicating potential targets of checkpoint control. Finally, expression of the immune checkpoint molecule $\mathrm{T}$ cell immunoglobulin mucin receptor 3 (TIM3; also known as HAVCR2) was significantly increased on key populations of lymphocytes in P. falciparum-infected patients ${ }^{29}$.

There are four mouse models of malaria that display the major symptoms and pathology of human disease and are routinely used to study malarial pathogenesis (BOX 3). A definitive role for PD1 in malarial pathogenesis was established when PD1-deficient mice were shown to rapidly and completely clear Plasmodium chabaudi infections, which usually cause chronic malaria in mice ${ }^{21}$. Notably, during the acute phase of $P$. chabaudi infection, PD1 was shown to mediate a $95 \%$ loss in the numbers and functional capacity of parasite-specific $\mathrm{CD}^{+} \mathrm{T}$ cells, which are required to control chronic disease $\mathrm{e}^{21}$.

Recent studies of malaria using four mouse models revealed a novel regulatory function for PDL2 (also known as B7-DC) ${ }^{9}$. It was shown that whereas 


\section{Box 2 | Overview of immune checkpoint molecules in cancer therapy}

Below, we describe three checkpoint molecules that are currently targeted for cancer therapy and one being tested in clinical trials. Therapies targeting several other immune checkpoint pathways have also shown promise for controlling various cancers, and some of these drugs have progressed to clinical trials (TABLE 1; REF. 108).

\section{CTLA4}

Cytotoxic T lymphocyte antigen 4 (CTLA4) is a member of the immunoglobulin superfamily and is expressed by activated T cells together with the T cell co-stimulatory protein CD28. Both molecules bind to CD80 and CD86 on dendritic cells (DCs), but CTLA4 binds with greater affinity and avidity than CD28. Whereas CD28 transmits a stimulatory signal ${ }^{109}$, CTLA4 is able to outcompete CD28 for CD80 and CD86 binding to inhibit T cell functions ${ }^{110}$. Of note, CTLA4 expression on effector T cells is increased only after T cell receptor (TCR)-mediated and CD28-mediated T cell activation to permit downstream control of immunity.

\section{PD1}

Programmed cell death protein 1 (PD1) has potent inhibitory effects on immunity. PD1 is expressed on T cells, B cells, natural killer T cells, DCs and activated monocytes $^{111,112}$. PD1 has two ligands, programmed cell death 1 ligand 1 (PDL1) and PDL2. PD1 expression is upregulated on the surface of T cells within 24 hours of TCR stimulation, and the effects of PD1 ligation can be seen within a few hours ${ }^{113}$. Importantly, signalling in T cells through PD1 following engagement with PDL1 expressed on DCs and tumour cells attenuates TCR signalling and inhibits T cell population expansion, cytokine production and cytolytic function ${ }^{114}$. New studies demonstrate that the CD28-B7 co-stimulatory pathway is essential for effective PD1-targeted therapy in tumour-bearing mice and during chronic viral infection ${ }^{115}$.

\section{PDL1}

PDL1 drives PD1-mediated immune inhibition and is constitutively expressed on T cells, $B$ cells, macrophages and $D C s^{116}$, in non-lymphoid tissues such as the heart and lungs ${ }^{111}$, in parenchymal cells ${ }^{117}$, and on the surface of tumour cells ${ }^{118}$. Expression of PDL1, but not PDL2, is also detected at low levels on cardiac endothelium, pancreatic islets and syncytiotrophoblasts in the placenta, highlighting a role for PDL1 in immunological tolerance ${ }^{119}$. PDL1 blockade has also demonstrated efficacy in lung, bladder and other cancers $^{120-122}$.

\section{PDL2}

PDL2 is also an immune checkpoint inhibitor, but its function is not as well understood as that of PDL1, and thus its clinical utility is still being explored. The engagement of PD1 by PDL2 dramatically inhibits TCR-mediated proliferation and cytokine production by $\mathrm{CD}^{+}{ }^{+}$cells $^{123}$. Antigen-presenting cells (APCs) from PDL2-deficient mice demonstrated an increased potential to activate T cells, both in vitro and in vivo ${ }^{124}$, suggesting that PDL2 has an inhibitory role similar to PDL1. However, recent studies showed PDL2 expressed as an aggregated form on DCs could inhibit PDL1 and/or PD1 binding and increase $\mathrm{CD} 3$ and inducible T cell co-stimulator (ICOS) expression on T cells, possibly via a putative second receptor ${ }^{9}$. Previous studies also showed that PDL2 could improve T cell function via a PD1-independent mechanism ${ }^{125-127}$. Thus, PDL2 has a complex function, and PDL2 proteins are being investigated in clinical trials.

PDL1 expressed by DCs did indeed attenuate immune responses against malaria, PDL2 protein expressed on the same DCs improved immune responses by inhibiting PDL1-PD1 interactions 9 . These studies also showed that PDL2 was essential for establishing effective $T_{H} 1$ cell immunity for protection against lethal malaria (FIG. 2). This study also examined healthy human volunteers before and after infection with experimental P. falciparum malaria. The authors found that the expression of PDL2, but not PDL1, on blood DCs decreased significantly within 7 days of infection to levels that inversely correlated with the level of parasitaemia in each individual ${ }^{9}$. In other words, higher PDL2 levels correlated with lower parasitaemia, indicating that this was not just a feature of mouse malaria. Overall, this study highlighted the importance of PDL2 expression for malarial immunity.
Immune checkpoint blockade in malaria. A recent study showed that a multimeric form of PDL2 fused with the Fc region of immunoglobulin (PDL2-Fc) given to mice infected with lethal malaria was sufficient to attenuate the lethal infection and mediate survival following reinfections after several months, without additional PDL2-Fc 9 (FIG. 2). Furthermore, combined blockade of the inhibitory molecules PDL1 and lymphocyte activation gene 3 protein (LAG3; also known as CD223) with antibodies accelerated the clearance of acute non-lethal blood-stage malaria (Plasmodium yoelii) by improving $\mathrm{CD}^{+} \mathrm{T}$ cell function and increasing antibody titres ${ }^{26}$. Finally, antibody-mediated triggering of OX40 signalling also improved $\mathrm{CD}^{+} \mathrm{T}$ helper cell and humoral immunity and thus parasite clearance during non-lethal malarial infections ${ }^{30}$.

During Plasmodium berghei infections in mice resistant to cerebral malaria, antibody-mediated blockade of either CTLA4 or PDL1, but not PDL2, resulted in higher levels of T cell activation with improved IFN $\gamma$ production but increased the incidence of cerebral malaria in these mice ${ }^{31}$. This was most likely because CTLA4 or PDL1 blockade did not improve CD4 ${ }^{+} \mathrm{T}$ cell functions sufficiently to control systemic parasite growth and sequestration in the brain before improved CD8 ${ }^{+}$ $\mathrm{T}$ cell functions could cause bystander pathology in the brain. By contrast, administering soluble multimeric PDL2-Fc fusion protein reduced the incidence of cerebral malaria by $78 \%{ }^{9}$. Similarly, blocking TIM3 signalling with an antibody restored lymphocyte activity in Plasmodium infections, resulting in accelerated parasite clearance and reduced symptoms of cerebral disease in P. berghei-infected mice ${ }^{29}$. The suppressive function of $\mathrm{T}_{\text {reg }}$ cells in lethal $P$. yoelii-infected mice was inhibited by GITR blockade, indicating another potential target ${ }^{32}$. $\mathrm{B}$ and T lymphocyte attenuator (BTLA; also known as CD272) has also been associated with cerebral malaria, and blockade of this inhibitory molecule significantly reduced the incidence of cerebral malaria compared with control mice ${ }^{33}$.

Overall, several checkpoint proteins contribute to the pathogenesis of malaria, and further investigation of their potential as therapeutic targets is warranted. These therapies may also have the potential to be used to 're-invigorate' immune cells, which are suggested to be non-responsive in areas where malaria is endemic ${ }^{26,27}$, to allow vaccines to generate long-term immunity. Alternatively, checkpoint blockade could complement malarial drugs to generate long-term immunity, as seen for PDL2-Fc 9 .

\section{Immune checkpoint proteins in HIV}

There are 37 million people living with HIV, and each year there are 2 million new infections and 1 million deaths ${ }^{34}$. Antiretroviral therapy (ART) has dramatically reduced HIV-related morbidity and mortality, but only $40 \%$ of people living with HIV globally are receiving $\mathrm{ART}^{34}$, and there is no vaccine or cure. Lifelong ART is required, as once treatment is stopped, the virus rapidly rebounds. Given the social and economic impact of the lifelong medical care required for people living with 
Table 1 | Summary of other major immune checkpoint pathways

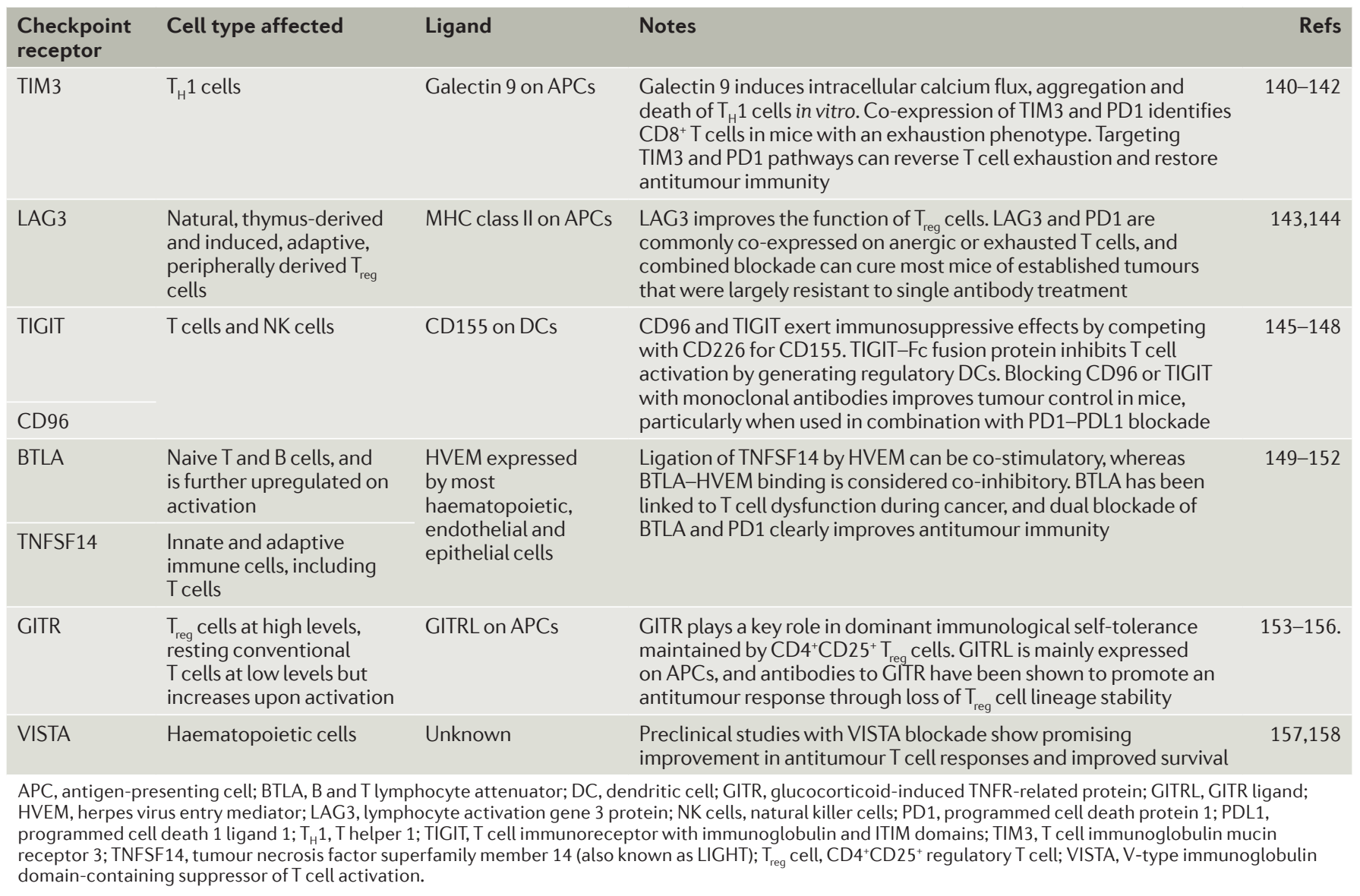

HIV, finding a cure has become a major global priority $^{35}$. Immune checkpoint proteins have been extensively studied during HIV infection, initially in relation to natural history and $\mathrm{T}$ cell function, but more recently in relation to complications of HIV infection. In addition, using immune checkpoint blockade could potentially be exploited as a strategy to achieve a cure.

T cell exhaustion and immune checkpoint proteins in HIV infection. T cell exhaustion is a hallmark of many chronic viral infections, including HIV. In untreated HIV infection, there is upregulated expression of multiple immune checkpoint proteins, including PD1, CTLA4, TIM3 and LAG3, on both CD4 ${ }^{+}$and $\mathrm{CD}^{+} \mathrm{T}$ cells ${ }^{36-38}$. Following ART, expression of immune checkpoint proteins declines but remains elevated compared with controls not infected with $\mathrm{HIV}^{38}$. Whether ART is started early (within 6 months of infection) or late (within 2 years of infection), similar expression levels of immune checkpoint proteins persist $^{39}$. In HIV infection, expression of immune checkpoint proteins varies on different $\mathrm{T}$ cell subsets. Increased expression of PD1 is predominantly seen on central memory T cells $\mathrm{s}^{40}$, whereas both PD1 and CTLA4 are expressed by $\mathrm{T}_{\text {reg }}$ cells and LAG3 is expressed by effector memory $\mathrm{T}$ cells ${ }^{41}$ (FIG. 3). In addition, PD1 is often co-expressed with proteins that help to promote $\mathrm{T}$ cell activation, such as CD38 and MHC class II molecules ${ }^{42}$.
Increased levels of PD1 expression on total and HIV-specific $\mathrm{CD}^{+} \mathrm{T}$ cells in untreated HIV infection were first reported more than 10 years ago ${ }^{36,43,44}$. $\mathrm{PD} 1$ is also highly expressed by cytotoxic $\mathrm{CD}^{+} \mathrm{T}$ cells that migrate into lymphoid follicles; these follicular cytotoxic $\mathrm{CD}^{+} \mathrm{T}$ cells express high levels of CXCchemokine receptor 5 (CXCR5) and PD1 but low levels of other immune checkpoint proteins, such as TIM3 (REF. 45). There is an inverse association between the frequency of cytotoxic $\mathrm{CD}^{+} \mathrm{T}$ cells and HIV-infected cells in lymphoid follicles, and a similar inverse relationship has been recently observed in untreated simian immunodeficiency virus (SIV) infection $^{45-47}$. Finally, ex vivo blockade with anti-PD1 or anti-PDL1 antibodies resulted in improved $\mathrm{HIV}$-specific $\mathrm{CD}^{+} \mathrm{T}$ cell function and killing of infected target cells ${ }^{36,43,44}$ (TABLE 2), as described for cancer antigens.

Multiple observational studies have demonstrated a clear association between expression of PD1 on either $\mathrm{CD}^{+}$or $\mathrm{CD}^{+} \mathrm{T}$ cells and clinical outcome. In the absence of ART, increased expression of PD1 was associated with an accelerated decline in the number of $\mathrm{CD} 4^{+} \mathrm{T}$ cells following acute infection ${ }^{48}$ and untreated chronic infection ${ }^{36}$. Following ART, PD1 expression on $\mathrm{CD}^{+} \mathrm{T}$ cells has been associated with impaired $\mathrm{CD}^{+} \mathrm{T}$ cell immune reconstitution ${ }^{49}$, microvascular 


\section{Box 3 | Mouse models of malaria}

Mouse models of malaria have provided useful information regarding the extent to which checkpoint proteins inhibit natural immunity. Four of the species and strains of Plasmodium most commonly used to infect mice show distinct biology and pathogenicity. Plasmodium yoelii 17XNL and Plasmodium chabaudi blood-stage infections are non-lethal, with the latter causing chronic disease with intermittent parasitaemia for up to 200 days. By contrast, Plasmodium yoelii YM and Plasmodium berghei ANKA infections are severe, lethal infections, with the latter being sequestered from the blood into deep tissues including the brain, leading to lethal cerebral disease. on partially suppressive ART, ipilimumab led to a modest increase in both $\mathrm{HIV}$-specific $\mathrm{CD}^{+}{ }^{+}$and $\mathrm{CD} 8^{+} \mathrm{T}$ cells and a significant reduction in cell-associated HIV RNA in lymph nodes ${ }^{59}$. These data therefore suggest that anti-CTLA4 antibody has a substantial effect on HIV that persists on ART, through a different mechanism of action to anti-PD1 antibody, leading to a reduction in HIV RNA in lymph node tissue. However, the mechanism by which this is achieved or whether there is antibody activity in individuals infected with HIV and on fully suppressive ART remains unknown.

In individuals infected with HIV, LAG3 is also highly expressed on $\mathrm{CD}^{+}$and $\mathrm{CD} 8^{+} \mathrm{T}$ cells in lymph nodes and blood, and this expression is directly related to levels of HIV RNA in plasma but inversely related to $\mathrm{CD}^{+}$ $\mathrm{T}$ cell counts ${ }^{41}$. Expression of $\mathrm{T}$ cell immunoreceptor with immunoglobulin and ITIM domains (TIGIT) is also increased on $\mathrm{CD}^{+} \mathrm{T}$ cells in untreated and treated HIV infection compared with controls without HIV ${ }^{38}$ even following early initiation of ART ${ }^{60}$. HIV-specific $\mathrm{CD}^{+}{ }^{+} \mathrm{T}$ cells were almost exclusively $\mathrm{TIGIT}^{+}$and coexpressed PD1, CD160 and 2B4 (also known as CD244) ${ }^{60}$. HIV-specific TIGIT $^{\text {hi }}$ cells were also negatively correlated with polyfunctionality and had reduced expression of the co-stimulatory receptor CD226. Blockade of TIGIT and PD1 with anti-TIGIT and anti-PDL1 antibodies ex vivo led to a significant improvement of the HIV-specific function of $\mathrm{CD}^{+} \mathrm{T}$ cells from individuals infected with HIV and on $\mathrm{ART}^{38}$. Antibodies against LAG3, TIM3 and TIGIT are all in early clinical development and, given their more favourable safety profiles, may be more suitable agents to assess in individuals infected with HIV ${ }^{61}$.

Immune checkpoint proteins and HIV persistence. In contrast to malignant cells, which traditionally express the ligands for immune checkpoint proteins such as PDL1 (REF. 62), in individuals infected with HIV and on ART, immune checkpoint proteins themselves identify cells preferentially infected with HIV that persist on ART $^{63,64}$ (FIG. 4). This observation is of great importance in efforts to eliminate residual virus that persists despite ART, as these infected cells are a major barrier to a cure. Although HIV can persist in multiple forms in individuals infected with HIV who are on ART, latently infected cells are the most important. Latency can be established in long-lived and proliferating central and transitional memory $\mathrm{T}$ cells as well as other $\mathrm{T}$ cell subsets, including $\mathrm{T}$ follicular helper $\left(\mathrm{T}_{\mathrm{FH}}\right)$ cells and stem cell memory $\mathrm{T}$ cells (reviewed in REF. 35).

Many studies have shown a significant correlation between the frequency of $\mathrm{PD} 1{ }^{+} \mathrm{CD} 4{ }^{+} \mathrm{T}$ cells and $\mathrm{PD}^{+}{ }^{+} \mathrm{CD} 8^{+} \mathrm{T}$ cells with different markers of HIV persistence on ART in the blood ${ }^{63,65,66}$, lymph nodes ${ }^{67}$ and gastrointestinal tract, which has almost three times the frequency of $\mathrm{PD} 1^{+} \mathrm{CD} 4^{+} \mathrm{T}$ cells compared with the lymph nodes or blood ${ }^{68}$. However, the most direct evidence of a clear relationship between HIV persistence and PD1 expression comes from sorting CD $4^{+} \mathrm{T}$ cells from blood, where a 10 -fold enrichment of HIV in $\mathrm{PD} 1{ }^{\text {hi }} \mathrm{CD} 4^{+} \mathrm{T}$ cells compared with $\mathrm{PD} 1^{\text {low }} \mathrm{CD} 4^{+} \mathrm{T}$ cells was observed ${ }^{63}$. Similar findings were also reported from 


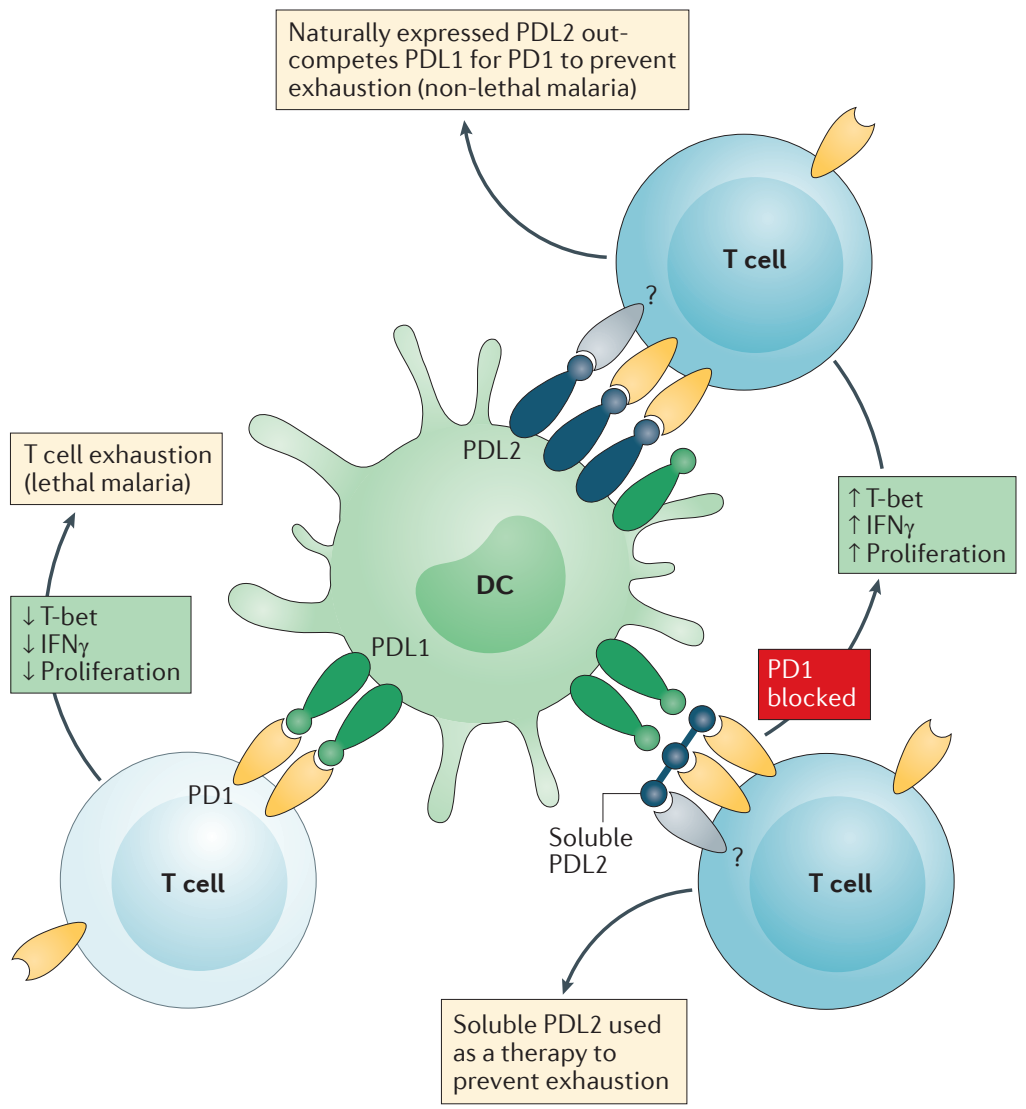

Figure 2 | PDL2 protects against lethal malaria and has translational potential. The expression of programmed cell death 1 ligand 2 (PDL2) on dendritic cells (DCs) determines effector T cell function following a programmed cell death protein 1 (PD1)PDL1 interaction. During non-lethal malaria (top right), DCs express PDL2, which inhibits the immunosuppressive PD1-PDL1 interaction while interacting with an unknown receptor (denoted by '?') to improve T cell functions. This leads to protective immunity characterized by increased T-bet expression, increased IFN $\gamma$ secretion and greater T cell proliferation in response to the parasite. By contrast, during lethal malaria (left), PDL2 expression is low or absent, and this allows the immunosuppressive PD1-PDL1 interaction to generate exhausted T cells, which do not express T-bet, do not secrete IFN $\gamma$ and cannot proliferate in response to the parasite. Soluble PDL2 administered to mice infected with lethal malaria (lower right) can prevent $\mathrm{T}$ cell exhaustion.

lymph node tissue collected from individuals infected with HIV and on ART, where HIV was highly enriched in cells expressing PD1 and CXCR5, which together identify $\mathrm{T}_{\mathrm{FH}}$ cells ${ }^{67}$ (FIG. 3). HIV enrichment in PD1 ${ }^{\text {hi }}$ cells may be due to the inhibitory effects of PD1 on T cell activation, which would limit HIV transcription, RNA export and RNA translation and therefore favour latent infection over productive infection (FIG. 4).

Immune checkpoint proteins other than PD1 may also identify infected cells in individuals on ART. We recently demonstrated that HIV was significantly enriched in sorted cells obtained from individuals infected with HIV on ART that expressed PD1, TIGIT and LAG3 compared with cells that expressed none of these immune checkpoint proteins ${ }^{64}$ (FIG. 3). The relationship between CTLA4 and virus persistence on ART has been less well studied. In untreated individuals, HIV replicates preferentially in activated $\mathrm{CD} 4^{+} \mathrm{T}$ cells, which express high levels of CTLA4, and therefore virus is enriched in CTLA4 ${ }^{+} \mathrm{CD} 4^{+} \mathrm{T}$ cells ${ }^{69}$. Rapid internalization of CTLA4, mediated by the viral protein Nef, may potentially play a role in favouring HIV persistence in these cells ${ }^{70}$. Whether latently infected CTLA $4^{+} \mathrm{CD} 4^{+} \mathrm{T}$ cells in the blood or tissues persist on ART is currently unclear.

These exciting observations are now being exploited by using immune checkpoint blockers to potentially reverse latency, allowing for expression of HIV proteins on the surface of the cell, which would lead to immune clearance of the virus or virus-induced cytolysis (FIG. 4). Latency reversal would be attempted in individuals on ART, so that any new virus produced could not go on to infect other cells. Through the use of $\mathrm{CD} 4^{+}$ T cells from individuals with HIV infection on ART, the ex vivo administration of anti-PD1 antibody together with the latency-reversing agent bryostatin led to a significant increase in HIV RNA released into the supernatant (N. Chomont, personal communication). In addition, in an individual infected with HIV on ART with metastatic melanoma, we observed a significant increase in cell-associated HIV RNA following treatment with anti-CTLA4 (ipilimumab) ${ }^{71}$ and anti-PD1 (nivolumab) antibodies $^{72}$. These results need to be confirmed in other HIV-infected individuals on ART who are now receiving checkpoint blockade for the management of cancer. The effects of other immune checkpoint blockers on latency establishment or reversal are unknown and warrant further exploration using antibodies, either alone or in combination.

Clinical trials of immune checkpoint blockade as a strategy for curing HIV. A phase II dose-escalation study of anti-PDL1 antibody therapy (by Bristol-Myers Squibb) was recently ceased after administration of the lowest dose to six individuals with HIV infection on $\mathrm{ART}^{73}$. The study was stopped due to retinal toxicity observed in a simultaneous macaque study. Interestingly, although there were no changes in levels of HIV RNA or DNA, there was a clear increase in Gag-specific $\mathrm{CD} 4^{+}$ and $\mathrm{CD} 8^{+} \mathrm{T}$ cells in two of the six participants. One of the six participants developed hypophysitis many months after receiving anti-PDL1 antibody therapy. This study remains the only trial of an immune checkpoint blocker in individuals with HIV infection without malignancy, and further trials are unlikely to proceed until more safety data for these compounds are available.

To date, few individuals with HIV infection have received even the currently licensed immune checkpoint blockers, as individuals with HIV infection were excluded from the initial clinical trials of these agents. However, now that these drugs are licensed, many individuals with HIV infection are receiving these antibodies as part of clinical care. Several clinical trials in the US and France are currently evaluating the effects of anti-PD1 and anti-CTLA4 antibodies either alone or in combination on HIV-associated malignancies, as well as on markers of HIV persistence and HIV-specific immunity (reviewed in REF. 74).

In summary, immune checkpoint blockers could have multiple beneficial contributions towards achieving a cure or allowing individuals to safely stop ART (FIG. 4). First, the 


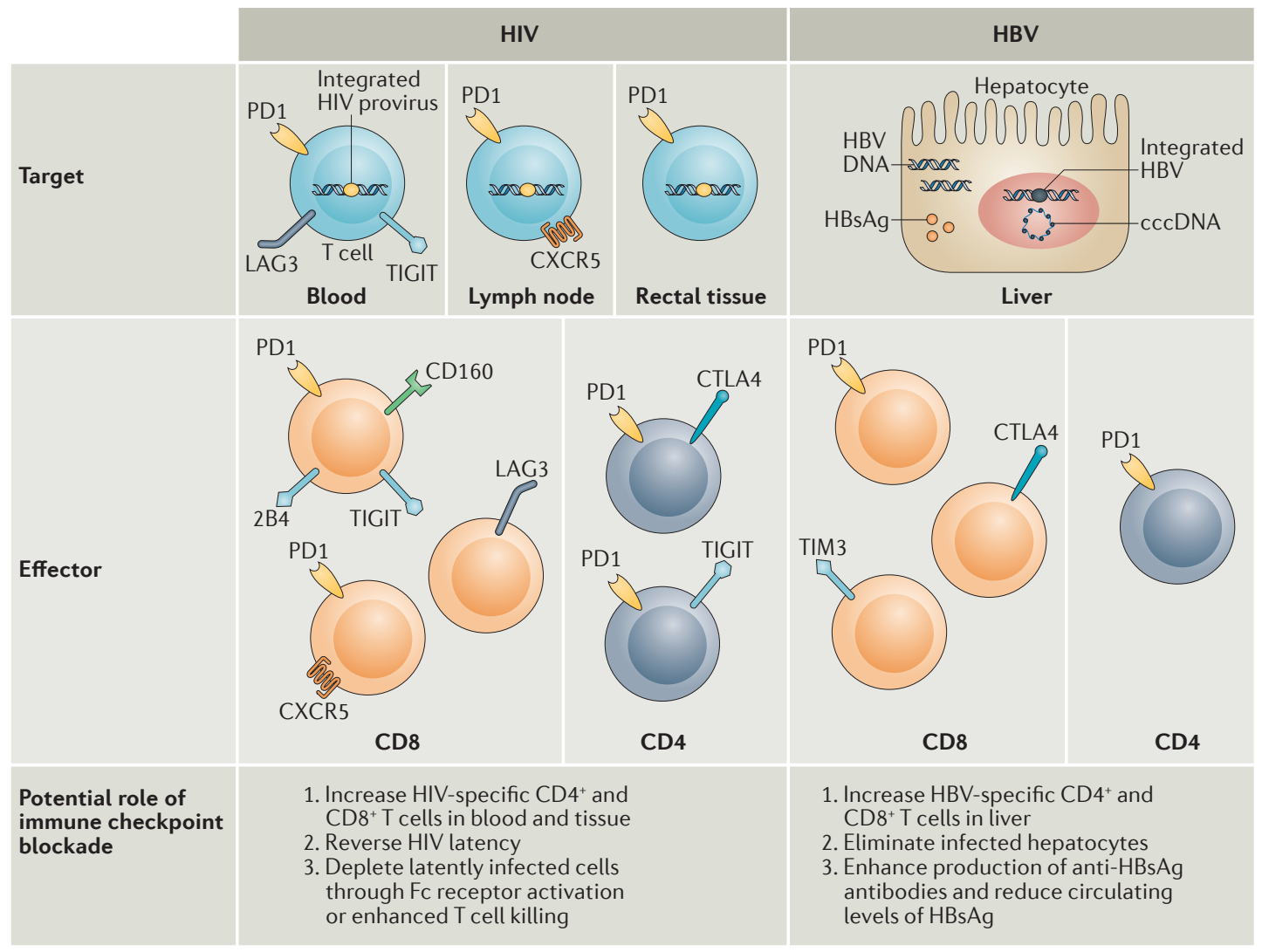

Figure 3 | Immune checkpoints in HIV and hepatitis B virus infection. In individuals infected with HIV who are on antiretroviral therapy (ART), the virus persists in latently infected $C D 4^{+} T$ cells as an integrated provirus; these T cells express programmed cell death protein 1 (PD1) and other immune checkpoint molecules in the blood, lymph nodes and rectal tissue. Immune checkpoint molecules are expressed on both HIV-specific and non-specific CD4 ${ }^{+}$and $\mathrm{CD} 8^{+} \mathrm{T}$ cells, and expression of these molecules by various T cell subsets, including central memory T cells, effector memory T cells, cytotoxic follicular T cells and regulatory T cells, is associated with T cell exhaustion and reduced T cell function. In hepatitis B virus (HBV) infection, HBV persists in individuals on treatment as extrachromosomal closed covalent circular (ccc) DNA and integrated HBV DNA, and there is ongoing production of hepatitis B surface antigen (HBsAg). Increased expression of immune checkpoint markers on $\mathrm{CD}^{+} \mathrm{T}$ cells and increased expression of PD1 on $\mathrm{CD} 4^{+} \mathrm{T}$ cells reduces $\mathrm{T}$ cell function. CTLA4, cytotoxic T lymphocyte antigen 4; CXCR5, CXC-chemokine receptor 5; LAG3, lymphocyte activation gene 3 protein; TIGIT, T cell immunoreceptor with immunoglobulin and ITIM domains; TIM3, T cell immunoglobulin mucin receptor 3.

administration of these drugs could potentially increase HIV-specific T cell function to eliminate HIV-infected cells. Second, they may lead to direct elimination of infected cells that express the relevant immune checkpoint marker, particularly when using a depleting antibody that activates Fc receptors, as described for ipilimumab ${ }^{75}$ and modified antibodies against PD1 (REF. 76). Third, immune checkpoint blockers could potentially reverse HIV latency. Finally, immune checkpoint blockers can increase vaccine responsiveness ${ }^{77}$ and therefore could potentially be combined with other therapeutic vaccines in development.

\section{Immune checkpoint proteins in HBV infection}

$\mathrm{HBV}$ is a DNA virus that predominantly replicates in the hepatocytes of the liver. Following entry of HBV into a hepatocyte, there is production of intracellular covalently closed circular DNA (cccDNA), which produces multiple forms of HBV RNA and HBV proteins, including hepatitis B surface antigen (HBsAg), as well as HBV DNA, which is required to form new infectious virions. Globally, there are 250 million people living with chronic $\mathrm{HBV}^{78}$, and the main complications include end-stage cirrhosis and/or hepatocellular carcinoma $(\mathrm{HCC})^{79}$. HBV can be effectively treated with self-limited interferon therapy or, more commonly, with long-term antiviral treatment using nucleotide-nucleoside reverse transcriptase inhibitors (NRTIs). Similarly to ART in individuals with HIV infection, treatment with NRTIs is lifelong, and there is no cure for $\mathrm{HBV}^{80}$. However, in contrast to HIV, approximately $10-15 \%$ of individuals can safely stop NRTI treatment for HBV without viral rebound. Inducing antiviral-free remission for $\mathrm{HBV}$ is possible with the development of antibodies to HBsAg, commonly referred to as seroconversion ${ }^{80}$.

\section{T cell exhaustion and immune checkpoint proteins in} $H B V$ infection. HBV-specific T cells are important in HBV pathogenesis, where they play a role in the initial clearance of acute infection, abnormal liver function commonly observed in acute and chronic infection, 
Table 2 | Summary of preclinical or ex vivo studies in infectious diseases reporting benefits of targeting inhibitory proteins

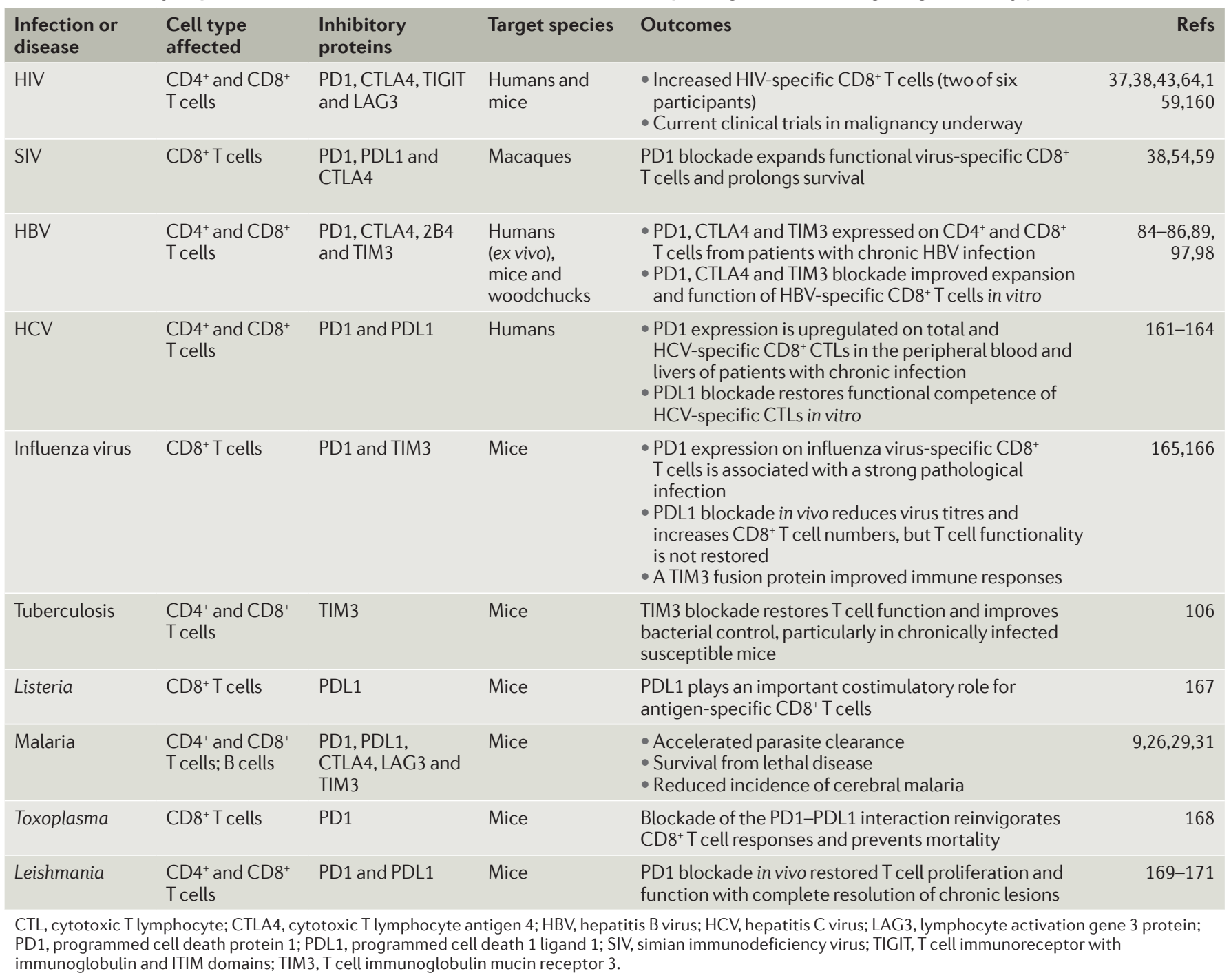

development of cirrhosis and successful HBsAg seroconversion following antiviral treatment (reviewed in REF. 81). The role and phenotype of HBV-specific $\mathrm{T}$ cells are different at each of these clinical stages, as circulating and intrahepatic HBV-specific T cells are infrequent in individuals chronically infected with HBV compared with individuals who have cleared acute HBV infection ${ }^{82,83}$.

In untreated chronic HBV infection, total and HBVspecific $\mathrm{CD} 8^{+} \mathrm{T}$ cells express high levels of PD1, CTLA4 and TIM3 (REFS 84-86), and in acute HBV infection, circulating and intrahepatic $\mathrm{CD} 8^{+} \mathrm{T}$ cells express high levels of PD1 (REF. 87; FIG. 3). The upregulation of PD1 expression in acute HBV infection is thought to limit intrahepatic inflammation ${ }^{87}$. The ligand for PD1, PDL1, has also been shown to be elevated on circulating $\mathrm{CD} 14^{+}$ monocytes and $\mathrm{CD} 19^{+} \mathrm{B}$ cells in individuals with chronic HBV infection, liver cirrhosis and HCC and therefore may contribute to ongoing $\mathrm{T}$ cell exhaustion ${ }^{88}$. These exhausted antigen-specific $\mathrm{CD}^{+} \mathrm{T}$ cells are prone to apoptosis through co-expression of the pro-apoptotic protein BIM (also known as BCL-2L11) ${ }^{86}$. By contrast, HBV-specific $\mathrm{CD}^{+}{ }^{+} \mathrm{T}$ cells, defined by MHC class II tetramers and HBV core peptides, expressed increased levels of PD1, but no increase in CTLA4, TIM3, KLRG1 or 2B4 expression was observed ${ }^{89}$ (summarized in FIG. 3).

A recent genome-wide expression-profiling study of $\mathrm{HBV}$-specific $\mathrm{CD} 8^{+} \mathrm{T}$ cells from individuals with acute and chronic HBV infection revealed extensive downregulation of multiple pathways, including pathways associated with mitochondrial function, and T cells from these individuals showed functional recovery in the presence of mitochondrial-targeted antioxidants ${ }^{90}$. These studies demonstrated that defects in $\mathrm{T}$ cell function in chronic HBV infection are not limited to increased expression of immune checkpoint proteins, although mitochondrial dysfunction was clearly enriched in $\mathrm{PD} 1^{\text {hi }} \mathrm{CD} 8{ }^{+} \mathrm{T}$ cells in this study ${ }^{90}$.

The phenotype of intrahepatic $\mathrm{CD} 4^{+}$and $\mathrm{CD} 8^{+}$ $\mathrm{T}$ cells has also been extensively characterized in HBV infection. Initial descriptions of intrahepatic T cells in chronic HBV infection showed a high infiltration 
a Establishing HIV latency
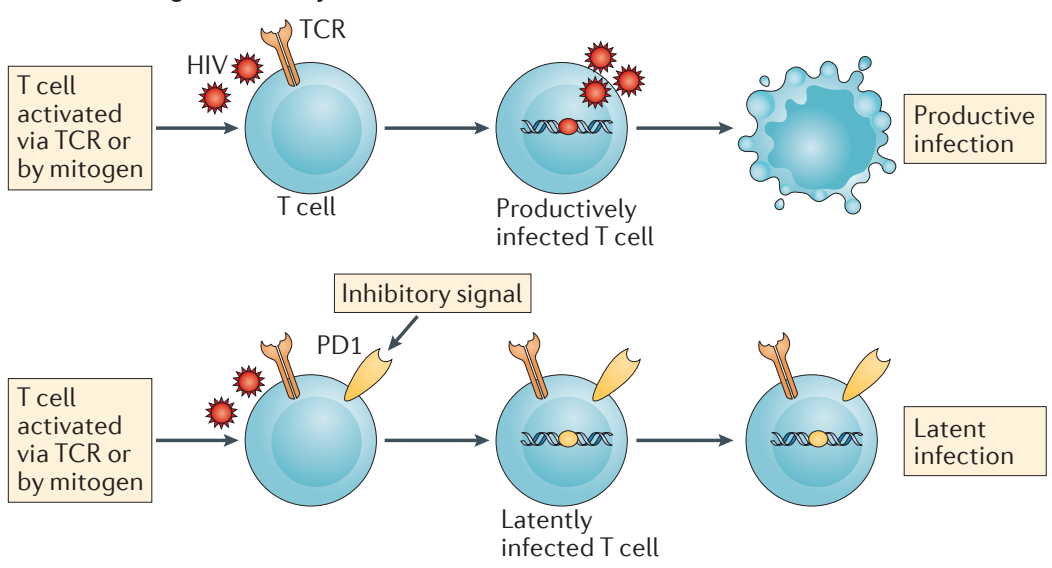

b Immune-mediated clearance

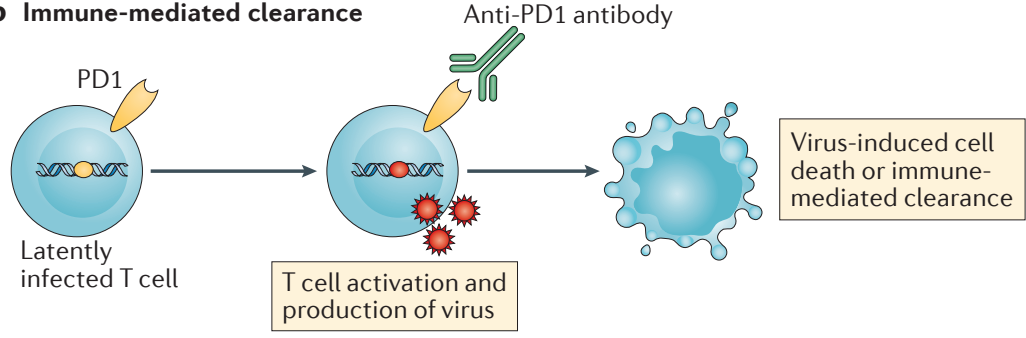

Figure 4 | Proposed role of PD1 in the establishment and reversal of HIV latency. a $\mid H I V$ preferentially infects activated $C D 4^{+} T$ cells that have been stimulated by $T$ cell receptor (TCR) engagement or by a mitogen. Following HIV integration, the productively infected cell usually dies by virus-mediated cytolysis. Upregulation of expression of immune checkpoint molecules, such as programmed cell death protein 1 (PD1), could potentially limit T cell activation, favouring latent infection, where there is integration of HIV (yellow oval) but no virus production. b | Latently infected T cells express immune checkpoint molecules, including PD1. The administration of anti-PD1 antibody, or other immune checkpoint blockers, leads to activation of these T cells and increased expression of transcription factors that can increase production of virus from latency. This treatment response leads to either immune-mediated clearance or virus-induced cell death.

of total and HBV-specific CD8 ${ }^{+} \mathrm{T}$ cells ${ }^{91}$. Intrahepatic T cells also show upregulation of PD1 (REF. 87) and TIM3 (REF. 84) expression. The ligand of TIM3, galectin 9, was also upregulated on Kupffer cells, perhaps allowing for persisting intrahepatic T cell exhaustion ${ }^{84}$. These intrahepatic $\mathrm{CD}^{+} \mathrm{T}$ cells also express other proteins of exhaustion, including BTLA, and can produce IL-10, which further inhibits effective $\mathrm{T}$ cell function ${ }^{92}$.

Immune checkpoint blockade as a strategy for curing $H B V$. Multiple ex vivo studies using blood collected from individuals with chronic HBV infection have demonstrated that inhibition of PD1, CTLA4, 2B4 and TIM3 leads to increased HBV-specific CD8 ${ }^{+} \mathrm{T}$ cell function $^{83,84,86,93-96}$. By contrast, only blockade of PD1 and not blockade of the other inhibitory proteins partially improved $\mathrm{HBV}$-specific $\mathrm{CD}^{+} \mathrm{T}$ cell functions, with increased production of IFN $\gamma$, IL-2 and tumour necrosis factor (TNF) ${ }^{89}$. Checkpoint blockade, used either alone or in combination, may potentially increase the production of $\mathrm{HBV}$-specific $\mathrm{CD}^{+} \mathrm{T}$ cells and even the production of antibodies against HBsAg, but there are substantial theoretical risks, including increased infiltration of reinvigorated $\mathrm{T}$ cells into the liver, which could trigger inflammation, but this has not been demonstrated in preclinical studies or recent clinical trials.

The effects of PD1 blockade in vivo during HBV infection have been evaluated in mouse and woodchuck models. Blockade of the PD1-PDL1 or PD1PDL2 pathways with anti-PDL1 and anti-PDL2 antibodies in woodchuck hepatitis virus (WHV)infected animals partially restored $\mathrm{T}$ cell function without hepatotoxicity ${ }^{97}$. In a separate study of WHV, the combination of antivirals (entecavir), therapeutic vaccination and anti-PDL1 antibody blockade, followed by cessation of entecavir, did not result in rebound of WHV in plasma and instead led to the development of antibodies against WHV surface antigens, with complete viral clearance in some animals ${ }^{98}$. Interestingly, the addition of anti-PDL1 antibody to the vaccine and entecavir arm compared with the vaccine and entecavir alone arm led to a significantly increased immunological and clinical response and was not associated with hepatotoxicity ${ }^{98}$. These studies look very promising for similar interventions to achieve sustained remission off NRTIs in human clinical trials.

A recent open-label study of nivolumab (anti-PD1 antibody; $0.3 \mathrm{mg}$ per $\mathrm{kg}$ ) with and without an $\mathrm{HBV}$ vaccine involving 20 participants with virally suppressed chronic HBV infection showed that nivolumab was safe and well tolerated, and one participant underwent HBsAg seroconversion ${ }^{99}$. Many other clinical trials of immune checkpoint blockade in individuals with chronic HBV, usually in the setting of HCC, are currently underway. One major study is a phase $1 / 2$, open-label, non-comparative, dose escalation and expansion trial (CheckMate 040 ) of nivolumab in adults ( $\geq 18$ years) with histologically confirmed advanced HCC with or without $\mathrm{HCV}$ or HBV infection ${ }^{100}$. Symptomatic treatment-related adverse events were similar in patients with and without $\mathrm{HCV}$ or $\mathrm{HBV}$ infection ${ }^{100}$, which is encouraging and the trial recently led to the licensing of nivolumab for HCC. Future cohorts within CheckMate040 which includes individuals with $\mathrm{HBV}$ on antiviral therapy will also examine nivolumab with other agents, including anti-CTLA-4 (NCT01658878). Another 60-month observational study, led by the Taiwan Food and Drug Administration, is also in progress (NCT02402699). This is a study of individuals in Taiwan with known HBV or $\mathrm{HCV}$ infection, regardless of control on antiviral therapy, and who are being treated with ipilimumab for advanced (unresectable, recurrent or metastatic) melanoma. Many other studies of immune checkpoint blockade for HCC that do not specifically exclude individuals with chronic HBV are currently enrolling participants.

In summary, immune checkpoint proteins play an important role in the natural history of $\mathrm{HBV}$ infection, limiting liver damage in acute infection and potentially facilitating persistent infection in chronic $\mathrm{HBV}$ infection. Initial studies indicate that nivolumab is safe in chronic HBV infection, but further studies are needed to determine whether anti-PD1 antibody and/or other immune checkpoint blockers can be used to induce HBV remission. 


\section{Immune checkpoint proteins in tuberculosis}

Mycobacterium tuberculosis, the causal agent of TB, is one of the ten most fatal diseases worldwide, with 10.4 million symptomatic infections and 1.8 million deaths (including 0.4 million among people co-infected with HIV) recorded in 2015. M. tuberculosis characteristically infects the lungs but can also affect any other organ of the body. TB is treatable and curable if the active, drug-susceptible infection is treated with a standard 6-month course of four antimicrobial drugs. However, the prevalence of multidrug-resistant TB is now increasing and requires longer treatment and more complicated antibiotic regimens.

$\mathrm{CD}^{+} \mathrm{T}$ cells are required for host resistance to M. tuberculosis. TB-specific CD4 ${ }^{+} \mathrm{T}$ cells in individuals with active TB infection were found to produce IFN $\gamma$, IL-2 and TNF and express PD1 (REF. 101). However, $\mathrm{PD} 1$ expression levels on total CD4 ${ }^{+} \mathrm{T}$ cells from individuals with active infection were only slightly higher those on than cells from healthy donors ${ }^{102}$. Notably, HIV and TB co-infection was consistently and independently associated with a reduced frequency of mycobacterial-specific CD4 ${ }^{+} \mathrm{T}$ cells secreting both IFN $\gamma$ and IL-2, and the proportion correlated inversely with HIV RNA levels in plasma ${ }^{101}$.

Mouse models used to determine the contribution of PD1 to TB pathogenesis have yielded conflicting results. Surprisingly, mice with a deletion of $P d c d 1$, which encodes PD1, showed increased pathology, and $\mathrm{PD} 1$-deficient $\mathrm{CD} 4^{+} \mathrm{T}$ cells are sufficient to trigger early mortality ${ }^{103,104}$. The lungs of the PD1-deficient mice showed uncontrolled bacterial proliferation and focal necrotic areas with predominantly neutrophilic infiltrates, but a lower number of infiltrating $\mathrm{T}$ and $\mathrm{B}$ cells ${ }^{105}$. Pro-inflammatory cytokines such as TNF and IL-6 were significantly increased in the lungs and sera of these mice, consistent with aberrant inflammation ${ }^{105}$. Notably, TB-specific T cell proliferation was dramatically reduced in PD1-deficient mice compared with controls due to an increased number of $\mathrm{T}_{\text {reg }}$ cells and recruitment of mesenchymal stem cells ${ }^{104}$. Similarly, functionally exhausted $\mathrm{TIM}^{+}{ }^{+} \mathrm{T}$ cells were shown to accumulate during chronic TB infection, and TIM3 blockade restored $\mathrm{T}$ cell functions and improved control of the bacterial load in chronically infected susceptible mice ${ }^{106}$.

The treatment of multidrug-resistant TB (that is, in which the bacteria shows resistance in vitro to at least isoniazid and rifampicin) is complicated. To obtain a clinical and a microbiological cure, individuals are treated for long periods because of the lower effectiveness of the second-line and third-line drugs ${ }^{107}$. Longterm exposure to these drugs, characterized by a poor safety and tolerability profile, reduces the adherence by individuals. The combination of these drugs with checkpoint inhibition may allow immunity to develop when the bacterial burden is under even partial control. For these reasons, checkpoint blockade during chronic TB infection requires further consideration.

\section{Conclusion}

Studies of the interplay between immune activation and suppression have shown an important role for immune checkpoint proteins in the pathogenesis of infectious diseases and malignancies. Notably, immune checkpoint blockade has revolutionized the treatment of cancer with remarkable success. A number of studies have suggested that immune checkpoint blockade may also be highly relevant for treating several infectious diseases, including malaria, HIV infection, HBV infection and TB (TABLE 2); in these diseases where drug resistance remains a challenge,

\section{Box $4 \mid$ Adverse reactions and limited durability associated with immune checkpoint blockade}

Blocking of checkpoint protein interactions with antibodies has shown to remarkably increase antitumour immunity; however, this immunity can be accompanied by immune-related adverse events resembling autoimmune disease ${ }^{128}$. Immune-related adverse events can occur in up to $90 \%$ of patients treated with an anti-cytotoxic T lymphocyte antigen 4 (CTLA4) antibody ${ }^{129}$ and $70 \%$ of patients treated with anti-programmed cell death protein 1 (PD1) and/or anti-programmed cell death 1 ligand 1 (PDL1) antibodies ${ }^{130,131}$. These immune-related adverse events typically originate in the skin, gastrointestinal tract, liver and endocrine system, although other organ systems may also be affected ${ }^{132}$. While treatment with immunosuppressive drugs such as prednisolone is effective and usually resolves the symptoms, these adverse effects can be fatal. Therefore, substantial concerns remain around using these antibodies in otherwise healthy individuals living with HIV or hepatitis B virus (HBV). Autoimmune toxicities such as colitis, myocarditis and pneumonitis occur more commonly with anti-CTLA4 than anti-PD1 antibody treatment, and whether these can be reduced through modifications of the antibodies and/or reduction in dosage needs to be considered when exploring their use for infectious diseases.

Other factors that could reduce the efficacy of immunotherapies include non-responsiveness to treatment and limited durability of restored T cell functions. Blockade of the PD1-PDL1 pathway has shown durable benefit in melanoma and other cancers ${ }^{130,131,133}$, but $>50 \%$ of patients do not respond or develop resistance to anti-PD1 antibody therapy. PD1 also plays a role in the setting of both acute and chronic infections. Whereas PD1 transcription is rapidly downregulated in functional antigen-specific $\mathrm{CD} 8^{+} \mathrm{T}$ cells that develop during acute infection, persistent TCR ligation during chronic viral infections maintains increased levels of PD1 transcription and the generation of a distinct lineage of non-functional 'exhausted' antigen-specific $\mathrm{CD} 8^{+} \mathrm{T}$ cells $\mathrm{s}^{134,135}$. These changes in T cell functions are persistent as a result of epigenetic modification, specifically demethylation of the promoter of PDCD1, which encodes PD1. These epigenetic changes persist even with reduction in antigen, as seen following effective antiviral therapy for HIV infection or following anti-PD1 antibody therapy ${ }^{136-139}$. Thus, for infectious diseases, immunotherapy may have optimal effects when used with a vaccine to minimize immune suppression and thus permit vaccine responses to develop. Alternatively, immunotherapy used in conjunction with antimicrobial agents could allow long-term immunity to develop once the acute symptomatic infection has been controlled. 
effective vaccine development has not been possible, or lifelong drug treatment is necessary. It should be recognized, however, that immune checkpoint blockade may also cause immune-related adverse events, as CTLA4, PD1, LAG3 and TIM3 are also involved in the regulation of peripheral tolerance to prevent autoimmunity (BOX 4).
Furthermore, whether there will be variable responses to immune checkpoint blockade and clinical outcomes for infectious diseases also remains to be determined. Despite this, immune checkpoint blockade may be an important new strategy for tackling chronic infections for which we are still lacking effective therapies or vaccines.
1. Baumeister, S. H., Freeman, G. J., Dranoff, G. \& Sharpe, A. H. Coinhibitory pathways in immunotherapy for cancer. Annu. Rev. Immunol. 34, 539-573 (2016)

2. Pardoll, D. M. The blockade of immune checkpoints in cancer immunotherapy. Nat. Rev. Cancer 12 252-264 (2012)

3. Wherry, E. J. T cell exhaustion. Nat. Immunol. 12 , 492-499 (2011)

4. Larkin, J. et al. Combined nivolumab and ipilimumab or monotherapy in untreated melanoma. N. Engl. J. Med. 373, 23-34 (2015).

5. Brahmer, J. R. et al. Phase I study of single-agent antiprogrammed death-1 (MDX-1106) in refractory solid tumors: safety, clinical activity, pharmacodynamics, and immunologic correlates. J. Clin. Oncol. 28, 3167-3175 (2010)

6. Chen, P. L. et al. Analysis of immune signatures in longitudinal tumor samples yields insight into biomarkers of response and mechanisms of resistance to immune checkpoint blockade. Cancer Discov. 6 , 827-837 (2016).

7. Kamphorst, A. O et al. Proliferation of PD-1 + CD8 $\mathrm{T}$ cells in peripheral blood after PD-1-targeted therapy in lung cancer patients. Proc. Natl Acad. Sci. USA 114, 4993-4998 (2017).

8. Huang, A. C. et al. T-Cell invigoration to tumour burden ratio associated with anti-PD-1 response. Nature 545, 60-65 (2017).

9. Karunarathne, D. S. et al. Programmed death-1 ligand 2-mediated regulation of the PD-L1 to PD-1 axis is essential for establishing CD4+ T cell immunity. Immunity 45, 333-345 (2016).

An important study on the mechanism of the protective function of PDL2.

10. Cheng, Q., Kyle, D. E. \& Gatton, M. L. Artemisinin resistance in Plasmodium falciparum: a process linked to dormancy? Int. J. Parasitol. Drugs Drug Resist. 2, 249-255 (2012)

11. World Health Organization. World Malaria Report (WHO, 2016).

12. Olotu, A. et al. Four-year efficacy of RTS,S/AS01E and its interaction with malaria exposure. N. Engl. J. Med. 368, 1111-1120 (2013).

13. Barragan, A., Kremsner, P. G., Weiss, W., Wahlgren, M. \& Carlson, J. Age-related buildup of humoral immunity against epitopes for rosette formation and agglutination in African areas of malaria endemicity. Infect. Immun. 66, 4783-4787 (1998).

14. Bull, P. C. et al. Parasite antigens on the infected red cell surface are targets for naturally acquired immunity to malaria. Nat. Med. 4, 358-360 (1998).

15. Soe, S. et al. Premunition against Plasmodium falciparum in a malaria hyperendemic village in Myanmar. Trans. R. Soc. Trop. Med. Hyg. 95, 81-84 (2001).

16. Mazier, D. et al. Hepatic phase of malaria is the target of cellular mechanisms induced by the previous and the subsequent stages. A crucial role for liver nonparenchymal cells. Immunol. Lett. 25, 65-70 (1990).

17. Cohen, S., McGregor, I. \& Carrington, S. Gammaglobulin and acquired immunity to human malaria. Nature 192, 733-737 (1961)

18. Langhorne, J., Simon-Haarhaus, B. \& Meding, S. J. The role of $\mathrm{CD} 4^{+} \mathrm{T}$ cells in the protective immune response to Plasmodium chabaudi in vivo. Immunol. Lett. 25, 101-107 (1990).

19. Podoba, J. E. \& Stevenson, M. M. CD4 ${ }^{+}$and $C D 8^{+} \mathrm{T}$ lymphocytes both contribute to acquired immunity to blood-stage Plasmodium chabaudi AS. Infect. Immun. 59, 51-58 (1991).

20. von der Weid, T., Honarvar, N. \& Langhorne, J. Genetargeted mice lacking $B$ cells are unable to eliminate a blood stage malaria infection. J. Immunol. 156 2510-2516 (1996)

21. Horne-Debets, J. M. et al. PD-1 dependent exhaustion of $\mathrm{CD} 8{ }^{+} \mathrm{T}$ cells drives chronic malaria. Cell Rep. $\mathbf{5}$, 1204-1213 (2013).
The first study to show a role for $\mathrm{CD}^{+} \mathrm{T}$ cells in controlling blood-stage malaria.

22. Horne-Debets, J. M. et al. Mice lacking Programmed cell death-1 show a role for $\mathrm{CD}^{+}{ }^{+} \mathrm{T}$ cells in long-term immunity against blood-stage malaria. Sci. Rep. 6, 26210 (2016)

23. Wykes, M. N., Zhou, Y. H., Liu, X. Q. \& Good, M. F. Plasmodium yoelii can ablate vaccine-induced longterm protection in mice. J. Immunol. 175 2510-2516 (2005)

24. Liu, X. Q. et al. Malaria infection alters the expression of B-cell activating factor resulting in diminished memory antibody responses and survival. Eur. J Immunol 42 3291-3301 (2012).

25. Pierce, S. K. \& Miller, L. H. World Malaria Day 2009 what malaria knows about the immune system that immunologists still do not. J. Immunol. 182. 5171-5177 (2009).

26. Butler, N. S. et al. Therapeutic blockade of PD-L1 and LAG-3 rapidly clears established blood-stage Plasmodium infection. Nat. Immunol. 13, 188-195 (2012).

The first study to show that checkpoint blockade during malaria could improve protective immunity.

27. Illingworth, J. et al. Chronic exposure to Plasmodium falciparum is associated with phenotypic evidence of $B$ and T cell exhaustion. J. Immunol. 190, 1038-1047 (2013).

28. Goncalves-Lopes, R. M. et al. Surface expression of inhibitory (CTLA-4) and stimulatory (OX40) receptors by $\mathrm{CD}_{4}{ }^{+}$regulatory $\mathrm{T}$ cell subsets circulating in human malaria. Microbes Infect. 18, 639-648 (2016).

29. Hou, N. et al. T-Cell immunoglobulin- and mucindomain-containing molecule 3 signaling blockade improves cell-mediated immunity against malaria. J. Infect. Dis. 214, 1547-1556 (2016)

30. Zander, R. A. et al. PD-1 co-inhibitory and OX40 co-stimulatory crosstalk regulates helper $\mathrm{T}$ cel differentiation and anti-plasmodium humoral immunity. Cell Host Microbe 17, 628-641 (2015)

31. Hafalla, J. C. et al. The CTLA-4 and PD-1/PD-L1 inhibitory pathways independently regulate host resistance to plasmodium-induced acute immune pathology. PLoS Pathog. 8, e 1002504 (2012).

32. Hisaeda, H. et al. Resistance of regulatory T cells to glucocorticoid-induced TNFR family-related protein (GITR) during Plasmodium yoelii infection. Eur. J. Immunol. 35, 3516-3524 (2005).

33. Lepenies, B. et al. Ligation of B and T lymphocyte attenuator prevents the genesis of experimental cerebral malaria. J. Immunol. 179, 4093-4100 (2007).

34. GBD 2015 HIV Collaborators et al. Estimates of global, regional, and national incidence, prevalence, and mortality of HIV, 1980-2015: the Global Burden of Disease Study 2015. Lancet HIV 3, e361-e387 (2016).

35. Deeks, S. G. et al. International AIDS Society global scientific strategy: towards an HIV cure 2016. Nat. Med. 22, 839-850 (2016).

36. Trautmann, L. et al. Upregulation of PD-1 expression on HIV-specific $\mathrm{CD}^{+} \mathrm{T}$ cells leads to reversible immune dysfunction. Nat. Med. 12, 1198-1202 (2006).

One of the first papers to identify PD1 as a marker of $\mathrm{T}$ cell exhaustion in HIV infection.

37. Kaufmann, D. E. et al. Upregulation of CTLA-4 by HIVspecific $C D 4^{+} \mathrm{T}$ cells correlates with disease progression and defines a reversible immune dysfunction. Nat. Immunol. 8, 1246-1254 (2007)

38. Chew, G. M. et al. TIGIT marks exhausted T cells, correlates with disease progression, and serves as a target for immune restoration in HIV and SIV Infection. PLoS Pathog. 12, e 1005349 (2016). An examination of TIGIT and PD1 in T cell exhaustion in HIV infection both on and off ART.

39. Rutishauser, R. et al. Early and delayed antiretroviral therapy (ART) result in comparable reductions in CD8 ${ }^{+}$ $\mathrm{T}$ cell exhaustion marker expression. AIDS Res Hum Retroviruses 33, 658-667 (2017).
40. Zhang, J. Y. et al. PD-1 up-regulation is correlated with HIV-specific memory CD8 ${ }^{+}$T-cell exhaustion in typical progressors but not in long-term nonprogressors. Blood 109, 4671-4678 (2007).

41. Tian, X. et al. The upregulation of LAG-3 on T cells defines a subpopulation with functional exhaustion and correlates with disease progression in HIVinfected subjects. J. Immunol. 194, 3873-3882 (2015).

42. Sauce, D. et al. PD-1 expression on human CD8 T cells depends on both state of differentiation and activation status. AIDS 21, 2005-2013 (2007).

43. Day, C. L. et al. PD-1 expression on HIV-specific T cells is associated with T-cell exhaustion and disease progression. Nature 443, 350-354 (2006).

44. Petrovas, C. et al. PD-1 is a regulator of virus-specific CD8 ${ }^{+}$T cell survival in HIV infection. J. Exp. Med. 203, 2281-2292 (2006).

45. Leong, Y. A. et al. CXCR5 ${ }^{+}$follicular cytotoxic T cells control viral infection in B cell follicles. Nat. Immunol. 17, 1187-1196 (2016)

46. Mylvaganam, G. H. et al. Dynamics of SIV-specific CXCR5 + CD8 T cells during chronic SIV infection. Proc. Natl Acad. Sci. USA 114, 1976-1981 (2017).

47. Li, S. et al. Simian immunodeficiency virus-producing cells in follicles are partially suppressed by $\mathrm{CD}^{+}$cells in vivo. J. Virol. 90, 11168-11180 (2016)

48. Hoffmann, M. et al. Exhaustion of activated CD8 T cells predicts disease progression in primary HIV-1 Infection. PLoS Pathog. 12, e1005661 (2016).

49. Shive, C. L. et al. Inflammation perturbs the IL-7 axis, promoting senescence and exhaustion that broadly characterize immune failure in treated HIV infection. J. Acquir. Immune Def. Syndr. 71 483-492 (2016).

50. Sinha, A. et al. role of T-cell dysfunction, inflammation, and coagulation in microvascular disease in HIV. J. Am. Heart Assoc. 5, e004243 (2016).

51. Kelesidis, T. et al. Oxidized lipoproteins are associated with markers of inflammation and immune activation in HIV-1 infection. AIDS 30, 2625-2633 (2016).

52. Hurst, J. et al. Immunological biomarkers predict HIV-1 viral rebound after treatment interruption. Nat. Commun. 6, 8495 (2015).

The first publication to show a functional link between expression of immune checkpoint proteins on T cells prior to ART and the time to rebound after cessation of ART. An important observation in determining the role of immune checkpoint proteins and HIV cure or remission.

53. Akhmetzyanova, l. et al. PD-L1 expression on retrovirus-infected cells mediates immune escape from CD8 ${ }^{+}$T cell killing. PLoS Pathog. 11, e 1005224 (2015).

54. Velu, V. et al. Enhancing SIV-specific immunity in vivo by PD- 1 blockade. Nature 458, 206-210 (2009).

55. Dyavar Shetty, R. et al. PD-1 blockade during chronic SIV infection reduces hyperimmune activation and microbial translocation in rhesus macaques. J. Clin. Invest. 122, 1712-1716 (2012).

56. Mylvaganam, G. H. et al. PD-1 blockade synergizes with ART for restoring anti-viral CD8 T cell function and possibly destabilizing the viral reservoir in SIV infected macaques [Abstract 9016]. Presented at the International AIDS Conference, Durban, South Africa, July 2016.

57. Gill, A. L. et al. Programed death-1/programed deathligand 1 expression in lymph nodes of HIV infected patients: results of a pilot safety study in rhesus macaques using anti-programed death-ligand 1 (Avelumab). AIDS 30, 2487-2493 (2016)

58. Cecchinato, V. et al. Immune activation driven by CTLA- 4 blockade augments viral replication at mucosal sites in simian immunodeficiency virus infection. J. Immunol. 180, 5439-5447 (2008).

59. Hryniewicz, A. et al. CTLA-4 blockade decreases TGF$\beta$, IDO, and viral RNA expression in tissues of SIVmac251-infected macaques. Blood 108 3834-3842 (2006). 
60. Tauriainen, J. et al. Perturbed CD8+ T cell TIGIT/ CD226/PVR axis despite early initiation of antiretroviral treatment in HIV infected individuals. Sci. Rep. 7, 40354 (2017).

61. Anderson, A. C., Joller, N. \& Kuchroo, V. K. Lag-3, Tim-3, and TIGIT: co-inhibitory receptors with specialized functions in immune regulation. Immunity 44, 989-1004 (2016)

62. Chatterjee, S. et al. A humanized antibody for imaging immune checkpoint ligand PD-L1 expression in tumors. Oncotarget 7, 10215-10227 (2016)

63. Chomont, N. et al. HIV reservoir size and persistence are driven by $T$ cell survival and homeostatic proliferation. Nat. Med. 15, 893-900 (2009)

The first demonstration of the relationship between PD1 and HIV persistence in patients on ART.

64. Fromentin, R. et al. CD4 ${ }^{+}$T cells expressing PD-1, TIGIT and LAG-3 contribute to HIV persistence during ART. PLoS Pathog. 12, e1005761 (2016). An important paper demonstrating that multiple immune checkpoint markers, not just PD1, are involved in HIV persistence in patients on ART.

65. Hatano, H. et al. Cell-based measures of viral persistence are associated with immune activation and programmed cell death protein 1 (PD-1)-expressing CD4 ${ }^{+}$T cells.. J. Infect. Dis. 208, 50-56 (2013).

66. Cockerham, L. R. et al. Programmed death-1 expression on $\mathrm{CD}^{+}$and $\mathrm{CD} 8{ }^{+} \mathrm{T}$ cells in treated and untreated HIV disease. AIDS 28, 1749-1758 (2014).

67. Banga, R. et al. PD-1 + and follicular helper T cells are responsible for persistent HIV-1 transcription in treated aviremic individuals. Nat. Med. 22, 754-761 (2016).

The first demonstration that $\mathrm{T}_{\mathrm{FH}}$ cells that express high levels of PD1 are an important reservoir for HIV in patients on ART.

68. Khoury, G. et al. HIV persistence and T-cell activation in blood, rectal and lymph node tissue in HIV-infected individuals receiving suppressive ART. J. Infect. Dis. 215, 911-919 (2017)

69. El-Far, M. et al. Nef promotes evasion of human immunodeficiency virus type 1 -infected cells from the CTLA-4-mediated inhibition of T-cell activation. J. Gen. Virol. 96, 1463-1477 (2015).

70. El-Far, M. et al. Down-regulation of CTLA-4 by HIV-1 Nef protein. PLOS ONE 8, e54295 (2013).

71. Wightman, F. et al. Effect of ipilimumab on the HIV reservoir in an HIV-infected individual with metastatic melanoma. AIDS 29, 504-506 (2015).

72. Van der Sluis, R. M. et al. Anti-PD-1 disrupts HIV latency in non-proliferating but not in proliferating T-cells [Abstract OA3-3]. J. Virus Eradication 3, Suppl. 1 (2017).

73. Gay, C. L. et al. Clinical trial of the anti-PD-L1 antibody BMS-936559 in HIV-1 infected participants on suppressive antiretroviral therapy. J. Infect. Dis. $\mathbf{2 1 5}$ 1725-1733 (2017).

74. Rasmussen, T. A., Anderson, J. L., Wightman, F. \& Lewin, S. R. Cancer therapies in HIV cure research. Curr. Opin. HIV AIDS 12, 96-104 (2017).

75. Romano, E. et al. Ipilimumab-dependent cell-mediated cytotoxicity of regulatory T cells ex vivo by nonclassical monocytes in melanoma patients. Proc. Natl Acad. Sci. USA 112, 6140-6145 (2015).

76. Dahan, R. et al. FcyRs modulate the anti-tumor activity of antibodies targeting the PD-1/PD-L1 axis. Cancer Cell 28, 285-295 (2015)

An interesting paper exploring the future direction of immune checkpoint blockers with modifications to the Fc tail so that the antibody activates Fc receptors.

77. Zhou, J. et al. PD1-based DNA vaccine amplifies HIVGAG-specific CD8 ${ }^{+} \mathrm{T}$ cells in mice. J. Clin. Invest. 123, 2629-2642 (2013)

78. Schweitzer, A., Horn, J., Mikolajczyk, R. T., Krause, G. $\&$ Ott, J. J. Estimations of worldwide prevalence of chronic hepatitis B virus infection: a systematic review of data published between 1965 and 2013. Lancet 386, 1546-1555 (2015)

79. Stanaway, J. D. et al. The global burden of viral hepatitis from 1990 to 2013: findings from the Global Burden of Disease Study 2013. Lancet 388 1081-1088 (2016)

80. Revill, P., Testoni, B., Locarnini, S. \& Zoulim, F. Global strategies are required to cure and eliminate HBV infection. Nat. Rev. Gastroenterol. Hepatol. 13 239-248 (2016)

81. Guidotti, L. G., Isogawa, M. \& Chisari, F. V. Host-virus interactions in hepatitis B virus infection. Curr. Opin. Immunol. 36, 61-66 (2015).
82. Chang, J. J. et al. The phenotype of hepatitis B virusspecific T cells differ in the liver and blood in chronic hepatitis B virus infection. Hepatology 46, 1332-1340 (2007).

83. Boni, C. et al. Characterization of hepatitis B virus (HBV)-specific T-cell dysfunction in chronic HBV infection. J. Virol. 81, 4215-4225 (2007).

84. Nebbia, G. et al. Upregulation of the Tim-3/galectin-9 pathway of T cell exhaustion in chronic hepatitis B virus infection. PLoS ONE 7, e47648 (2012).

85. Bengsch, B., Martin, B. \& Thimme, R. Restoration of HBV-specific CD8 ${ }^{+} \mathrm{T}$ cell function by PD-1 blockade in inactive carrier patients is linked to T cell differentiation. J. Hepatol. 61, 1212-1219 (2014).

86. Schurich, A. et al. Role of the coinhibitory receptor cytotoxic T lymphocyte antigen-4 on apoptosis-prone CD8 T cells in persistent hepatitis B virus infection. Hepatology 53, 1494-1503 (2011)

87. Zhang, Z. et al. Dynamic programmed death 1 expression by virus-specific CD8 T cells correlates with the outcome of acute hepatitis B. Gastroenterology 134, 1938-1949 (2008). A demonstration of the importance of PD1 expression in acute $\mathrm{HBV}$ infection.

88. Huang, Z. Y. et al. Clinical significance of dynamics of programmed death ligand-1 expression on circulating CD $14^{+}$monocytes and CD 19+ B Cells with the progression of Hepatitis $B$ virus infection. Viral Immunol. 30, 224-231 (2017)

89. Raziorrouh, B. et al. Inhibitory phenotype of HBVspecific CD4 ${ }^{+}$- -cells is characterized by high PD- 1 expression but absent coregulation of multiple inhibitory molecules. PLOS ONE 9, e 105703 (2014).

90. Fisicaro, P. et al. Targeting mitochondrial dysfunction can restore antiviral activity of exhausted HBV-specific CD8 T cells in chronic hepatitis B. Nat. Med. 23 327-336 (2017).

91. Maini, M. K. et al. The role of virus-specific $\mathrm{CD} 8^{+}$cells in liver damage and viral control during persistent hepatitis B virus infection. J. Exp. Med. 191, 1269-1280 (2000)

92. Wang, H. et al. Hepatic expansion of virus-specific CD8 ${ }^{+} \mathrm{BTLA}+\mathrm{T}$ cells with regulatory properties in chronic hepatitis B virus infection. Cell. Immunol. 311, 36-45 (2017)

93. Fisicaro, P. et al. Antiviral intrahepatic T-cell responses can be restored by blocking programmed death-1 pathway in chronic hepatitis B. Gastroenterology 138 682-693 (2010)

94. Raziorrouh, B. et al. The immunoregulatory role of CD244 in chronic hepatitis B infection and its inhibitory potential on virus-specific CD8 ${ }^{+} \mathrm{T}$-cell function. Hepatology 52, 1934-1947 (2010)

95. Isogawa, M., Furuichi, Y. \& Chisari, F. V. Oscillating $\mathrm{CD}^{+} \mathrm{T}$ cell effector functions after antigen recognition in the liver. Immunity 23, 53-63 (2005).

96. Maier, H., Isogawa, M., Freeman, G. J. ¿ Chisari, F. V. PD-1:PD-L1 interactions contribute to the functional suppression of virus-specific CD8 ${ }^{+} \mathrm{T}$ lymphocytes in the liver. J. Immunol. 178, 2714-2720 (2007).

97. Zhang, E. et al. The expression of PD-1 ligands and their involvement in regulation of $\mathrm{T}$ cell functions in acute and chronic woodchuck hepatitis virus infection. PLOS ONE 6, e26196 (2011).

98. Liu, J. et al. Enhancing virus-specific immunity in vivo by combining therapeutic vaccination and PD-L1 blockade in chronic hepadnaviral infection. PLoS Pathog. 10, e 1003856 (2014).

A study showing the effect of anti-PDL1 antibody in an animal model of HBV; it reduced viral rebound after cessation of antiviral therapy and increased antibodies to HBV surface antigen

99. Gane, E. J. et al. A phase 1 study evaluating anti-PD-1 treatment with or without GS-4774 in $\mathrm{HBeAg}$ negative chronic hepatitis B patients [Abstract]. Eur. Associ. Study Liver Dis. (2017).

100. El-Khoueiry, A. B. et al. Nivolumab in patients with advanced hepatocellular carcinoma (CheckMate 040): an open-label, non-comparative, phase $1 / 2$ dose escalation and expansion trial. Lancet $\mathrm{http}: / / \mathrm{dx}$.doi.org/10.1016/ S0140-6736(17)31046-2 (2017)

101. Pollock, K. M. et al. PD-1 expression and cytokine secretion profiles of Mycobacterium tuberculosisspecific CD4 ${ }^{+}$T-cell subsets; potential correlates of containment in HIV-TB co-Infection. PLOS ONE 11 e0146905 (2016)

102. Boer, M. C. et al. KLRG1 and PD-1 expression are increased on T-cells following tuberculosis-treatment and identify cells with different proliferative capacities in BCG-vaccinated adults. Tuberculosis (Edinb). 97 163-171 (2016).
103. Barber, D. L., Mayer-Barber, K. D., Feng, C. G. Sharpe, A. H. \& Sher, A. CD4 T cells promote rather than control tuberculosis in the absence of PD-1-mediated inhibition. J. Immunol. 186, 1598-1607 (2011)

104. Tousif, S. et al. T cells from programmed death-1 deficient mice respond poorly to Mycobacterium tuberculosis infection. PLOS ONE 6, e 19864 (2011).

105. Lazar-Molnar, E. et al. Programmed death-1 (PD-1)deficient mice are extraordinarily sensitive to tuberculosis. Proc. Natl Acad. Sci. USA 107. 13402-13407 (2010).

106. Jayaraman, P. et al. TIM3 mediates T cell exhaustion during Mycobacterium tuberculosis infection. PLoS Pathog. 12, e1005490 (2016).

107. Sotgiu, G., Centis, R., D'Ambrosio, L. \& Migliori, G. B. Tuberculosis treatment and drug regimens. Cold Spring Harb. Perspect Med. 5, a017822 (2015).

108. Attanasio, J. \& Wherry, E. J. Costimulatory and coinhibitory receptor pathways in infectious disease. Immunity 44, 1052-1068 (2016).

109. Harding, F. A., McArthur, J. G., Gross, J. A Raulet, D. H. \& Allison, J. P. CD28-mediated signalling co-stimulates murine $T$ cells and prevents induction of anergy in T-cell clones. Nature 356, 607-609 (1992).

110. Krummel, M. F. \& Allison, J. P. CD28 and CTLA-4 have opposing effects on the response of T cells to stimulation. J. Exp. Med. 182, 459-465 (1995) A seminal study of CTLA4.

111. Freeman, G. J. et al. Engagement of the PD-1 immunoinhibitory receptor by a novel B7 family member leads to negative regulation of lymphocyte activation. J. Exp. Med. 192, 1027-1034 (2000). A seminal study of the PD1-PDL1 interaction.

112. Keir, M. E., Butte, M. J., Freeman, G. J. \& Sharpe, A. H. PD- 1 and its ligands in tolerance and immunity. Annu. Rev. Immunol. 26, 677-704 (2008).

113. Chemnitz, J. M., Parry, R. V., Nichols, K. E., June, C. H. $\&$ Riley, J. L. SHP-1 and SHP-2 associate with immunoreceptor tyrosine-based switch motif of programmed death 1 upon primary human $\mathrm{T}$ cell stimulation, but only receptor ligation prevents $\mathrm{T}$ cell activation. J. Immunol. 173, 945-954 (2004).

114. Francisco, L. M. et al. PD-L1 regulates the development, maintenance, and function of induced regulatory T cells. J. Exp. Med. 206, 3015-3029 (2009).

115. Kamphorst, A. O. et al. Rescue of exhausted CD8 T cells by PD-1-targeted therapies is CD28-dependent. Science 355, 1423-1427 (2017). An important study highlighting the balance between immune activation and immune suppression.

116. Yamazaki, T. et al. Expression of programmed death ligands by murine T cells and APC. J. Immunol. 169 , 5538-5545 (2002).

117. Keir, M. E. et al. Tissue expression of PD-L1 mediates peripheral T cell tolerance. J. Exp. Med. 203 883-895 (2006)

118. Brown, J. A et al. Blockade of programmed deathligands on dendritic cells enhances $T$ cell activation and cytokine production. J. Immunol. 170 1257-1266 (2003).

119. Liang, S. C. et al. Regulation of PD-1, PD-L1, and PD-L2 expression during normal and autoimmune responses. Eur. J. Immunol. 33, 2706-2716 (2003).

120. Balar, A. V. et al. Atezolizumab as first-line treatment in cisplatin-ineligible patients with locally advanced and metastatic urothelial carcinoma: a single-arm, multicentre, phase 2 trial. Lancet 389, 67-76 (2017).

121. Rittmeyer, A. et al. Atezolizumab versus docetaxel in patients with previously treated non-small-cell lung cancer (OAK): a phase 3, open-label, multicentre randomised controlled trial. Lancet 389, 255-265 (2017)

122. Homet Moreno, B., Mok, S., Comin-Anduix, B., Hu-Lieskovan, S. \& Ribas, A. Combined treatment with dabrafenib and trametinib with immune-stimulating antibodies for BRAF mutant melanoma. Oncoimmunol. 5, e1052212 (2016).

123. Latchman, Y. et al. PD-L2 is a second ligand for PD-1 and inhibits T cell activation. Nat. Immunol. 2 , 261-268 (2001)

124. Zhang, Y. et al. Regulation of T cell activation and tolerance by PDL2. Proc. Natl Acad. Sci. USA 103, 11695-11700 (2006).

125. Tseng, S. Y. et al. B7-DC, a new dendritic cell molecule with potent costimulatory properties for $\mathrm{T}$ cells. J. Exp. Med. 193, 839-846 (2001). First study to highlight a protective role for PDL2. 
126. Shin, T. et al. Cooperative B7-1/2 (CD80/CD86) and B7-DC costimulation of $C D 4^{+} T$ cells independent of the PD-1 receptor. J. Exp. Med. 198, 31-38 (2003).

127. Shin, T. et al. In vivo costimulatory role of B7-DC in tuning T. helper cell 1 and cytotoxic T. lymphocyte responses. J. Exp. Med. 201, 1531-1541 (2005).

128. Michot, J. M. et al. Immune-related adverse events with immune checkpoint blockade: a comprehensive review. Eur. J. Cancer 54, 139-148 (2016).

129. Hodi, F. S. et al. Improved survival with ipilimumab in patients with metastatic melanoma. N. Engl. J. Med. 363, 711-723 (2010).

130. Topalian, S. L. et al. Safety, activity, and immune correlates of anti-PD- 1 antibody in cancer N. Engl. J. Med. 366, 2443-2454 (2012).

131. Brahmer, J. R. et al. Safety and activity of anti-PD-L1 antibody in patients with advanced cancer. N. Engl. J. Med. 366, 2455-2465 (2012).

132. Weber, J. S., Postow, M., Lao, C. D. \& Schadendorf, D. Management of adverse events following treatment with anti-programmed death-1 agents. Oncologist 21, 1230-1240 (2016).

133. Topalian, S. L. et al. Survival, durable tumor remission, and long-term safety in patients with advanced melanoma receiving nivolumab. J. Clin. Oncol. 32 , 1020-1030 (2014).

134. Barber, D. L. et al. Restoring function in exhausted CD8 T cells during chronic viral infection. Nature 439 682-687 (2006).

135. Wherry, E. J. et al. Molecular signature of $C D 8+T$ cell exhaustion during chronic viral infection Immunity 27, 670-684 (2007).

136. Youngblood, B. et al. Cutting edge: prolonged exposure to HIV reinforces a poised epigenetic program for PD-1 expression in virus-specific CD8 T cells. J. Immunol. 191, 540-544 (2013).

137. Ahn, E. et al. Demethylation of the PD-1 promoter is imprinted during the effector phase of CD8 T cell exhaustion. J. Virol 90, 8934-8946 (2016).

138. Pauken, K. E. et al. Epigenetic stability of exhausted T cells limits durability of reinvigoration by PD-1 blockade. Science 354, 1160-1165 (2016).

139. Sen, D. R. et al. The epigenetic landscape of T cell exhaustion. Science 354, 1165-1169 (2016). An important paper defining how $\mathrm{T}$ cell exhaustion is controlled at the epigenetic level.

140. Zhu, C. et al. The Tim-3 ligand galectin-9 negatively regulates T helper type 1 immunity. Nat Immunol 6 , 1245-1252 (2005).

141. Zhou, Q. et al. Coexpression of Tim-3 and PD-1 identifies a $\mathrm{CD}^{+}{ }^{+} \mathrm{T}$-cell exhaustion phenotype in mice with disseminated acute myelogenous leukemia. Blood 117, 4501-4510 (2011).

142. Sakuishi, K. et al. Targeting Tim-3 and PD- 1 pathways to reverse T cell exhaustion and restore anti-tumor immunity. J. Exp. Med. 207, 2187-2194 (2010).

143. Huang, C. T. et al. Role of LAG-3 in regulatory T cells. Immunity 21, 503-513 (2004).

144. Woo, S. R. et al. Immune inhibitory molecules LAG-3 and PD-1 synergistically regulate T-cell function to promote tumoral immune escape. Cancer Res. 72, 917-927 (2012)

145. Dougall, W. C., Kurtulus, S., Smyth, M. J. \& Anderson, A. C. TIGIT and CD96: new checkpoint receptor targets for cancer immunotherapy. Immunol. Rev. 276, 112-120 (2017).
146. Lozano, E., Dominguez-Villar, M., Kuchroo, V. \& Hafler, D. A. The TIGIT/CD226 axis regulates human T cell function. J. Immunol. 188, 3869-3875 (2012).

147. Yu, X. et al. The surface protein TIGIT suppresses T cell activation by promoting the generation of mature immunoregulatory dendritic cells. Nat. Immunol. 10 48-57 (2009).

148. Blake, S. J., Dougall, W. C., Miles, J. J., Teng, M. W. \& Smyth, M. J. Molecular pathways: targeting CD96 and TIGIT for cancer immunotherapy. Clin. Cancer Res. 22, 5183-5188 (2016)

149. Gonzalez, L. C. et al. A coreceptor interaction between the CD28 and TNF receptor family members B and T lymphocyte attenuator and herpesvirus entry mediator. Proc. Natl Acad. Sci. USA 102, 1116-1121 (2005)

150. Sedy, J. R. et al. B and T lymphocyte attenuator regulates $\mathrm{T}$ cell activation through interaction with herpesvirus entry mediator. Nat. Immunol. 6, 90-98 (2005).

151. Cai, G. \& Freeman, G. J. The CD160, BTLA, LIGHT/ HVEM pathway: a bidirectional switch regulating T-cell activation. Immunol. Rev. 229, 244-258 (2009).

152. Fourcade, J. et al. CD8 ${ }^{+} \mathrm{T}$ cells specific for tumor antigens can be rendered dysfunctional by the tumor microenvironment through upregulation of the inhibitory receptors BTLA and PD-1. Cancer Res. 72 887-896 (2012)

153. Ephrem, A. et al. Modulation of Treg cells/T effector function by GITR signaling is context-dependent. Eur. J. Immunol. 43, 2421-2429 (2013).

154. Shimizu, J., Yamazaki, S., Takahashi, T., Ishida, Y. \& Sakaguchi, S. Stimulation of CD25+CD4+ regulatory T cells through GITR breaks immunological selftolerance. Nat. Immunol. 3, 135-142 (2002).

155. Schaer, D. A., Cohen, A. D. \& Wolchok, J. D. Anti-GITR antibodies - potential clinical applications for tumor immunotherapy. Curr. Opin. Investig. Drugs 11, 1378-1386 (2010)

156. Mitsui, J. et al. Two distinct mechanisms of augmented antitumor activity by modulation of immunostimulatory/inhibitory signals. Clin. Cancer Res. 16, 2781-2791 (2010).

157. Deng, J., Le Mercier, I., Kuta, A. \& Noelle, R. J. A new VISTA on combination therapy for negative checkpoint regulator blockade. J. Immunother. Cancer 4, 86 (2016).

158. Gao, J. et al. VISTA is an inhibitory immune checkpoint that is increased after ipilimumab therapy in patients with prostate cancer Nat Med, 23, 551-555 (2017).

159. Freeman, G. J., Wherry, E. J., Ahmed, R. \& Sharpe, A. H. Reinvigorating exhausted HIV-specific $\mathrm{T}$ cells via PD-1-PD-1 ligand blockade. J. Exp. Med. 203, 2223-2227 (2006).

160. Kaufmann, D. E. \& Walker, B. D. PD-1 and CTLA-4 inhibitory cosignaling pathways in HIV infection and the potential for therapeutic intervention. J. Immunol. 182, 5891-5897 (2009).

161. Golden-Mason, L. et al. Upregulation of PD-1 expression on circulating and intrahepatic hepatitis $\mathrm{C}$ virus-specific CD8 ${ }^{+} \mathrm{T}$ cells associated with reversible immune dysfunction. J. Virol. 81, 9249-9258 (2007).

162. Nakamoto, N. et al. Functional restoration of HCVspecific CD8 T cells by PD-1 blockade is defined by PD-1 expression and compartmentalization. Gastroenterology 134, 1927-1937 (2008).

163. Lukens, J. R., Cruise, M. W., Lassen, M. G. \& Hahn, Y. S. Blockade of PD-1/B7-H1 interaction restores effector $\mathrm{CD} 8^{+} \mathrm{T}$ cell responses in a hepatitis $\mathrm{C}$ virus core murine model. J. Immunol. 180 4875-4884 (2008)

164. Urbani, S. et al. Restoration of HCV-specific T cell functions by PD-1/PD-L1 blockade in HCV infection: effect of viremia levels and antiviral treatment. J. Hepatol. 48, 548-558 (2008).

165. Rutigliano, J. A. et al. Highly pathological influenza A virus infection is associated with augmented expression of PD- 1 by functionally compromised virus-specific CD8+ T cells. J. Virol. 88, 1636-1651 (2014).

166. Sharma, S. et al. T cell immunoglobulin and mucin protein-3 (Tim-3)/Galectin-9 interaction regulates influenza A virus-specific humoral and CD8 T-cell responses. Proc Natl Acad Sci. USA 108 19001-19006 (2011).

167. Xu, D. et al. A potential new pathway for PD-L1 costimulation of the CD8-T cell response to Listeria monocytogenes infection. PLOS ONE 8, e56539 (2013)

168. Bhadra, R., Gigley, J. P., Weiss, L. M. \& Khan, I. A Control of Toxoplasma reactivation by rescue of dysfunctional CD8 ${ }^{+}$T-cell response via PD-1-PDL-1 blockade. Proc. Natl Acad. Sci. USA 108, 9196-9201 (2011)

169. Mou, Z. et al. Parasite-derived arginase influences secondary anti-Leishmania immunity by regulating programmed cell death-1-mediated $\mathrm{CD}^{+}{ }^{+} \mathrm{T}$ cell exhaustion. J. Immunol. 190, 3380-3389 (2013).

170. Esch, K. J., Juelsgaard, R., Martinez, P. A., Jones, D. E. $\&$ Petersen, C. A. Programmed death 1-mediated $T$ cell exhaustion during visceral leishmaniasis impairs phagocyte function. J. Immunol. 191, 5542-5550 (2013).

171. Joshi, T., Rodriguez, S., Perovic, V., Cockburn, I. A. \& Stager, S. B7-H1 blockade increases survival of dysfunctional $C D 8+T$ cells and confers protection against Leishmania donovani infections. PLoS Pathog. 5, e1000431 (2009).

\section{Acknowledgements}

The authors sincerely thank M. Flynn for the design and implementation of the figures. The authors acknowledge editorial assistance of S. Johnatty from SugarApple Communications in finalizing the manuscript. The authors thank N. Chomont, University of Montreal, for helpful comments and discussion. The authors acknowledge the support of The National Health and Medical Research Council (NHMRC) (Australia). S.R.L. is an NHMRC practitioner fellow and is supported by the National Institutes for Health Delaney AIDS Research Enterprise (DARE U19 AI1 26611 and AI096109) and the American Foundation for AIDS Research.

\section{Competing interests statement}

The authors declare competing interests: see Web version for details.

Author contributions

The authors contributed equally to researching, writing and editing the review.

\section{Publisher's note}

Springer Nature remains neutral with regard to jurisdictional claims in published maps and institutional affiliations. 